JGR Oceans

\author{
RESEARCH ARTICLE \\ 10.1029/2019JC015529 \\ Key Points: \\ - The seasonal cycle of vertical \\ turbulent cooling was assessed at \\ $4^{\circ} \mathrm{N}, 23^{\circ} \mathrm{W}$ and $15^{\circ} \mathrm{N}, 38^{\circ} \mathrm{W}$ \\ - Turbulent cooling of sea surface \\ temperature is strongest during \\ the seasons when mean winds are \\ weakest and the mixed layer is \\ thinnest \\ - Tropical instability waves \\ contributed $15-30 \mathrm{~W} \mathrm{~m}^{-2}$ of \\ monthly mean cooling at $4^{\circ} \mathrm{N}, 23^{\circ} \mathrm{W}$ \\ during May-July 2017 and May-July \\ 2019
}

Correspondence to:

G. R. Foltz,

gregory.foltz@noaa.gov

Citation:

Foltz, G. R., Hummels, R., Dengler, M., Perez, R. C., \& de Araujo, M. (2020). Vertical turbulent cooling of the mixed layer in the Atlantic ITCZ and trade wind regions. Journal of Geophysical Research: Oceans, 125, e2019JC015529. https://doi.org/10.1029/2019JC015529

Received 26 JUL 2019 Accepted 5 FEB 2020

Accepted article online 11 FEB 2020

\section{Vertical Turbulent Cooling of the Mixed Layer in the Atlantic ITCZ and Trade Wind Regions}

\author{
Gregory R. Foltz ${ }^{1}$ iD, Rebecca Hummels ${ }^{2}$, Marcus Dengler ${ }^{2}$ (D), Renellys C. Perez ${ }^{1}$ (D), \\ and Moacyr Araujo ${ }^{3,4}$ (i) \\ ${ }^{1}$ NOAA/Atlantic Oceanographic and Meteorological Laboratory, Miami, FL, USA, ${ }^{2}$ GEOMAR Helmholz Centre for \\ Ocean Research, Kiel, Germany, ${ }^{3}$ Department of Oceanography, DOCEAN, UFPE, University Federal Pernambuco, \\ Recife, Brazil, ${ }^{4}$ Brazilian Research Network on Global Climate Change, São José Dos Campos, Brazil
}

\begin{abstract}
The causes of the seasonal cycle of vertical turbulent cooling at the base of the mixed layer are assessed using observations from moored buoys in the tropical Atlantic Intertropical Convergence Zone (ITCZ) $\left(4^{\circ} \mathrm{N}, 23^{\circ} \mathrm{W}\right)$ and trade wind $\left(15^{\circ} \mathrm{N}, 38^{\circ} \mathrm{W}\right)$ regions together with mixing parameterizations and a one-dimensional model. At $4^{\circ} \mathrm{N}$ the parameterized turbulent cooling rates during 2017-2018 and 2019 agree with indirect estimates from the climatological mooring heat budget residual: both show mean cooling of 25-30 $\mathrm{W} \mathrm{m}^{-2}$ during November-July, when winds are weakest and the mixed layer is thinnest, and $0-10 \mathrm{~W} \mathrm{~m}^{-2}$ during August-October. Mixing during November-July is driven by variability on multiple time scales, including subdiurnal, near-inertial, and intraseasonal. Shear associated with tropical instability waves (TIWs) is found to generate mixing and monthly mean cooling of $15-30 \mathrm{~W} \mathrm{~m}^{-2}$ during May-July in 2017 and 2019 . At $15^{\circ} \mathrm{N}$ the seasonal cycle of turbulent cooling is out of phase compared to $4^{\circ} \mathrm{N}$, with largest cooling of up to $60 \mathrm{~W} \mathrm{~m}^{-2}$ during boreal fall. However, the relationships between wind speed, mixed layer depth, and turbulent mixing are similar: weaker mean winds and a thinner mixed layer in the fall are associated with stronger mixing and turbulent cooling of SST. These results emphasize the importance of seasonal modulations of mixed layer depth at both locations and shear from TIWs at $4^{\circ} \mathrm{N}$.
\end{abstract}

Plain Language Summary In the tropics, vertical turbulent mixing transports heat from the surface waters to the deeper ocean, regulating sea surface temperature (SST). Turbulent mixing has been shown to cause pronounced cooling of SST in the eastern equatorial Pacific and Atlantic Oceans. This cooling is driven to a large extent by strong vertical shear of the zonal equatorial currents, which give rise to instability and mixing. In this study the seasonal cycles of turbulent cooling are assessed at two off-equatorial locations in the tropical North Atlantic. Despite the different conditions at these two locations, it is found that turbulent cooling at both is strongest during the time of year when the mean winds are weakest and the mixed layer is thinnest. This is surprising, since it might be expected that stronger mean winds and associated deepening of the mixed layer would directly force much of the mixing and turbulent cooling at off-equatorial locations. Instead, the shallow mean mixed layer, which is more responsive to surface forcing, sets the stage for stronger bursts of cooling. In addition, intraseasonal variations in shear and mixing from tropical instability waves are important at $4^{\circ} \mathrm{N}$. These results will be useful for evaluating the mixing parameterizations used in numerical models.

\section{Introduction}

The tropical Atlantic experiences a strong seasonal cycle of sea surface temperature (SST) and weaker, but impactful, interannual to multidecadal variability (Carton \& Huang, 1994; Carton \& Zhou, 1997; Chiang et al., 2002; Foltz et al., 2019; Keenlyside \& Latif, 2007; Martín-Rey et al., 2018; Mitchell \& Wallace, 1992; Nobre \& Shukla, 1996). Outside of the Atlantic equatorial and Intertropical Convergence Zone (ITCZ) regions (together spanning $\sim 5^{\circ} \mathrm{S}$ to $10^{\circ} \mathrm{N}$ ) the seasonal cycle of SST has been shown to be forced to a large extent by local surface heat fluxes (Carton \& Zhou, 1997; Cintra et al., 2015; Foltz et al., 2003, 2013; Nogueira Neto et al., 2018; Yu et al., 2006). Close to the equator, upwelling and vertical turbulent mixing are thought to contribute significantly to SST variability (Foltz et al., 2003, 2013; Giordani et al., 2013; Hummels et al., 2013, 2014; Jouanno et al., 2011; Peter et al., 2006; Rhein \& Dengler, 2010; Wade et al., 2011; Yu et al., 2006).
(C)2020. American Geophysical Union. This article has been contributed to by US Government employees and their work is in the public domain in the USA. All Rights Reserved. 
Similar results have been found in the eastern equatorial Pacific (McPhaden et al., 2008; Moum et al., 2013; Swenson \& Hansen, 1999; Wang \& McPhaden, 1999).

The vertical turbulent heat flux at the base of the mixed layer is one of the most difficult terms to estimate because of the small spatial and temporal scales involved, yet it can be one of the larger terms in the mixed layer heat budget (Hummels et al., 2013; Moum et al., 2013). In the tropical Atlantic, previous studies of mixing have focused mainly on the eastern equatorial region, where mean cooling from turbulent mixing is large (Jouanno et al., 2011; Figure 1). Direct measurements of mixing near the equator in the Atlantic show strong seasonality and zonal dependence of the vertical turbulent heat flux, with strongest cooling near $10^{\circ} \mathrm{W}$ in boreal summer (Hummels et al., 2013). The seasonal and zonal variations appear to be driven by stratification and vertical shear of horizontal velocity. The shear variance below the mixed layer generally follows the seasonal cycle of near-surface currents, reaching a maximum in boreal spring and early summer and a minimum in September. Shear variance is larger and the thermocline is shallower between $10^{\circ} \mathrm{W}$ and $0^{\circ}$ than between $10^{\circ} \mathrm{W}$ and $23^{\circ} \mathrm{W}$ (Jouanno et al., 2011). However, stratification is stronger east of $10^{\circ} \mathrm{W}$, likely due to enhanced salinity stratification from precipitation and river outflow in the Gulf of Guinea (Jouanno et al., 2011). The enhanced stratification acts to stabilize the flow so that the greatest instability (i.e., lowest Richardson number) and turbulent cooling occur in the central equatorial Atlantic (near $10^{\circ} \mathrm{W}$ ) during boreal summer and fall.

These earlier results in the equatorial Atlantic emphasize the complex interplay between velocity shear and stratification. They also suggest that direct surface wind- and buoyancy-forced turbulence may make only minor contributions to turbulent cooling since the magnitudes of these terms are similar in the equatorial and off-equatorial regions, yet cooling is much weaker outside of $2^{\circ} \mathrm{S}$ to $2^{\circ} \mathrm{N}$. Indeed, microstructure profiles have revealed cooling of less than $15 \mathrm{~W} \mathrm{~m}^{-2}$ poleward of $2^{\circ}$ of latitude, with no spatial or seasonal dependence, in contrast to cooling of $95 \mathrm{~W} \mathrm{~m}^{-2}$ on the equator between $10^{\circ} \mathrm{W}$ and $23^{\circ} \mathrm{W}$ (Hummels et al., 2013, 2014). However, there is also evidence that near-inertial wave (NIW) events may contribute a substantial amount of cooling (Jochum et al., 2013). NIWs typically have frequencies close to the local Coriolis parameter, which translates to periods of about $2-2.5$ days at $11.5^{\circ} \mathrm{N}$. They have been shown to dissipate a substantial amount of internal wave energy in the global ocean and can be resonantly forced by wind stress with near-inertial frequencies (Alford et al., 2016; MacKinnon et al., 2017; Pollard \& Millard, 1970).

Indirectly, heat budget residuals also suggest significant annual mean and seasonally varying turbulent cooling off the equator (Figure 1; Foltz \& McPhaden, 2009; Foltz et al., 2013, 2018). At most locations, turbulent cooling was found to be strongest during the seasons when the wind is weakest and the mixed layer is thinnest (Foltz et al., 2018), suggesting that seasonal changes in winds and surface heat and buoyancy fluxes cannot directly explain the pronounced seasonal cycles of turbulent cooling. It is unknown what drives the seasonal cycle of off-equatorial cooling in the absence of the strong mean vertical current shear that exists between $2^{\circ} \mathrm{S}$ and $2^{\circ} \mathrm{N}$ associated with the westward South Equatorial Current and the underlying eastward Equatorial Undercurrent. Close to the mean latitude of the $\operatorname{ITCZ}\left(\sim 2-5^{\circ} \mathrm{N}\right)$, one possibility is enhanced mixing from tropical instability waves (TIWs). TIWs form vortices centered at about $4^{\circ} \mathrm{N}$ that propagate westward with periods of 20-50 days and advect cooler equatorial SSTs northward at their leading edges (Athie \& Marin, 2008; Caltabiano et al., 2005; Perez et al., 2012, 2019). They tend to be strongest in boreal summer, when the equatorial cold tongue of SST is well developed and there is strong meridional shear of the zonal currents between the westward South Equatorial Current and the eastward North Equatorial Countercurrent (Grodsky et al., 2005; von Schuckmann et al., 2008). In the equatorial Pacific, TIWs have been found to affect shear, stratification, turbulent mixing, and SST cooling (Moum et al., 2009; Inoue et al., 2012, 2019). They have also been hypothesized to play an important role in the mixed layer heat budget of the equatorial Atlantic (Foltz et al., 2003; Hummels et al., 2013; Jochum et al., 2004).

In this study we examine vertical turbulent cooling in the ITCZ and tropical North Atlantic trade wind regions, where there are distinct seasonal cycles of the mixed layer heat budget residual (Foltz et al., 2018; red contours in Figure 1). Our analysis combines measurements from long-term moored buoys and a glider and one-dimensional models to quantify seasonal variations of turbulent cooling. In contrast, most previous studies have focused mainly on the equatorial Atlantic and have used either heat budget residual estimates or microstructure profiles, from which it is difficult to resolve the seasonal cycle, or have relied entirely on ocean general circulation models. 


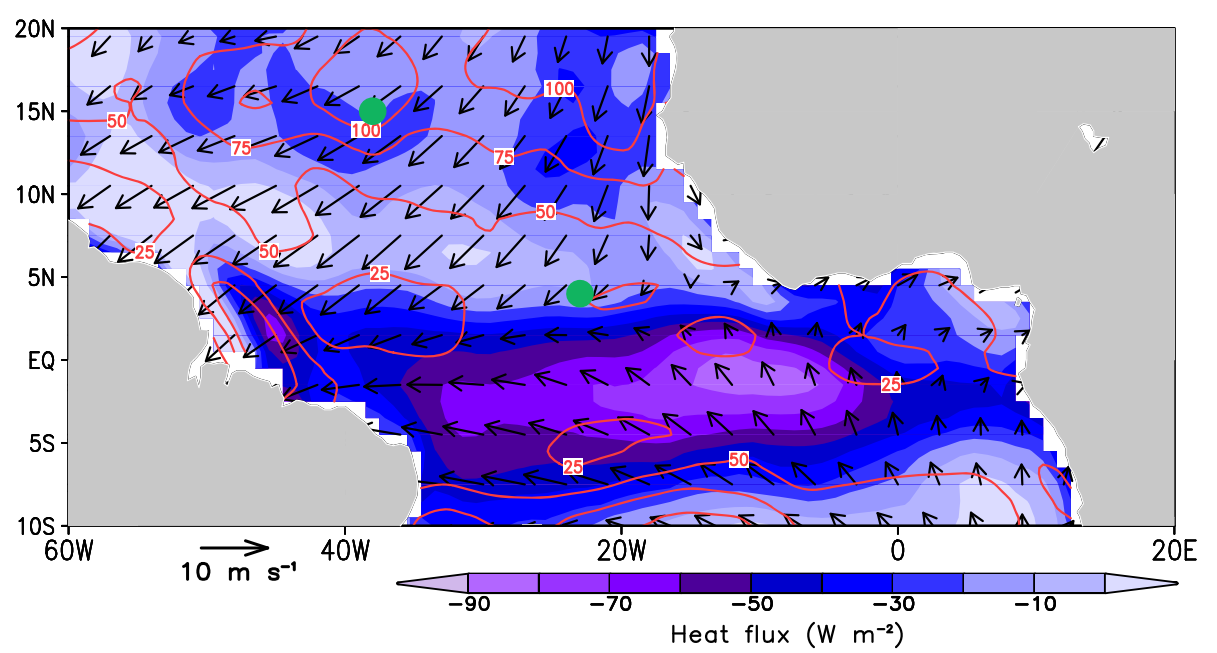

Figure 1. Annual mean mixed layer heat budget residual for the period 2003-2017 (shaded), an estimate of the vertical turbulent heat flux at the base of the mixed layer. Red contours show the amplitude of the monthly mean seasonal cycle of the residual, calculated as the monthly climatological maximum minus the minimum. Arrows show mean 10-m wind velocity averaged during 2003-2017. Green dots indicate the locations of PIRATA moorings used in this study.

\section{Data and Methods}

\subsection{PIRATA Mooring Data}

The main data set consists of hourly measurements from two buoys of the Prediction and Research Moored Array in the Tropical Atlantic (PIRATA; Bourlès et al., 2019; https://www.pmel.noaa.gov/tao/ drupal/disdel/) located at $4^{\circ} \mathrm{N}, 23^{\circ} \mathrm{W}$ and $15^{\circ} \mathrm{N}, 38^{\circ} \mathrm{W}$. These moorings are subsequently referred to as $4^{\circ} \mathrm{N}$ and $15^{\circ} \mathrm{N}$, respectively. Measurements from $4^{\circ} \mathrm{N}$ began in June 2006 and at $15^{\circ} \mathrm{N}$ in February 1998. Both moorings make standard meteorological measurements as well as ocean temperature, salinity, and horizontal velocity (Figure 2). During March 2017 to March 2018 and May-October 2019, the $4^{\circ} \mathrm{N}$ mooring was augmented with 10 additional current meters (Figure 2; Perez et al., 2019). Missing velocity data at a depth of $7 \mathrm{~m}$ (January-March 2018) are filled using linear extrapolation based on the values at 12 and $17 \mathrm{~m}$. Missing data at $37 \mathrm{~m}$ (June 2017 to March 2018) are filled with linear interpolation. Missing temperature data at the same depths are filled with linear interpolation. At $4^{\circ} \mathrm{N}$, two different mixing parameterizations are used to estimate the vertical eddy diffusivity, given hourly measurements from the mooring (see section 2.4). The diffusivity estimates are combined with temperature measurements from the mooring to calculate the vertical turbulent heat flux.

At $15^{\circ} \mathrm{N}$, there is no period with additional ocean velocity measurements for calculating shear and its impacts on vertical mixing. Therefore, the vertical turbulent heat flux at $15^{\circ} \mathrm{N}$ is estimated using a prognostic one-dimensional model initialized and forced with mooring data (see section 2.5). We use data during 2001-2004, 2006, 2007, and 2012, when hourly shortwave radiation measurements are available from the mooring to force the model.

In addition to hourly measurements directly from the moorings, at $4^{\circ} \mathrm{N}$ and $15^{\circ} \mathrm{N}$ we use the enhanced PIRATA data set (ePIRATA; Foltz et al., 2018; http://www.aoml.noaa.gov/phod/epirata/). At $15^{\circ} \mathrm{N}$, daily ePIRATA winds and latent, sensible, and longwave fluxes are used to force the one-dimensional ocean model along with hourly solar radiation directly from the mooring. We also use daily ePIRATA ocean temperature and salinity, available at depths of $1 \mathrm{~m}$ and at $5-\mathrm{m}$ intervals between $5 \mathrm{~m}$ and $200 \mathrm{~m}$, to initialize the model at $15^{\circ} \mathrm{N}$. At both locations, ePIRATA also provides estimates of vertical turbulent cooling of the mixed layer that are independent from those of the mixing parameterizations and one-dimensional model mentioned previously in this section. The rate of cooling is calculated as the ePIRATA heat budget residual $(R)$, equal to the mixed layer heat storage rate minus the sum of the net surface heat flux absorbed in the mixed layer and horizontal advection: $R=\rho c_{p} h \partial \bar{T} / \partial t-\left(Q_{0}-\rho c_{p} h \mathbf{v} \cdot \nabla T\right)$. Here $\rho$ is seawater density and $c_{p}$ is the specific heat, $h$ is mixed layer depth (MLD), $\bar{T}$ is vertically averaged mixed layer temperature, $Q_{0}$ is the net surface heat flux, and $\mathbf{v}$ is horizontal velocity vertically averaged in the mixed layer. The $\nabla \bar{T}$ term is calculated using centered differences of daily $1^{\circ} \times 1^{\circ}$ microwave-infrared satellite SST (http://www.remss.com/measurements/ 


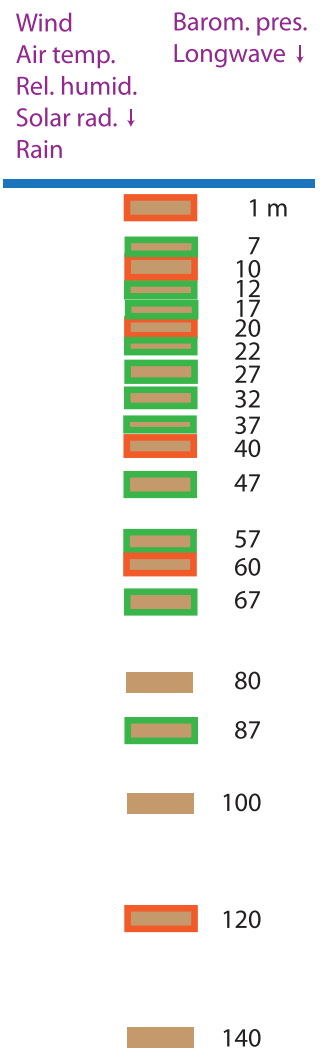

$4^{\circ} \mathrm{N}, 23^{\circ} \mathrm{W}$
Wind

Air temp.

Rel. humid.

Solar rad. $\downarrow$

Rain
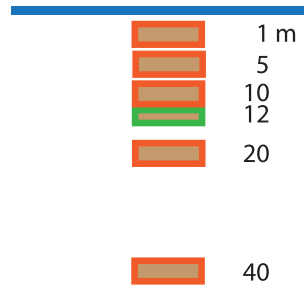

40

60

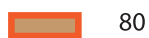

80

100

120

140

$15^{\circ} \mathrm{N}, 38^{\circ} \mathrm{W}$

\section{$\square \mathrm{T} \square \mathrm{T}, \mathrm{S} \square \mathrm{T}, \mathrm{v}$}

Figure 2. Ocean temperature $(T)$, salinity $(S)$, and velocity $(v)$, and atmospheric measurements, available from the PIRATA moorings used in this study.

sea-surface-temperature/). Error bars for the monthly mean seasonal cycle of the residual are calculated from the daily errors in ePIRATA, using a decorrelation time scale of 3 days and assuming monthly means for each year are independent of the monthly means in other years, following Foltz et al. (2018). The ePIRATA residuals represent vertical turbulent mixing and entrainment, the latter resulting from the combination of mixed layer deepening and divergence: $w_{e}=\partial h / \partial t+\nabla \cdot h \mathbf{v}$, where $w_{e}$ is entrainment velocity (Stevenson \& Niiler, 1983). The residuals also contain the accumulation of errors from other terms in the heat budget. It is important to take these errors into account when interpreting the residuals in terms of physical processes.

\subsection{Glider Turbulence Data}

Glider data used for this study were collected during the seventeenth deployment of glider IFM02 (Institut für Meereskunde 02 ) at $5^{\circ} \mathrm{N}, 23^{\circ} \mathrm{W}$ between 30 October and 6 November 2012. During this mission, the glider profiled along three waypoints set up in a triangle having edge length of four nautical miles about the deployment position. Details of the mission are provided at this site (https://gliderweb.geomar.de/html/real_glider. html). IFM02 is a Teledyne WebbResearch G1 deep glider (short version) equipped with an unpumped CTD and additional sensors measuring oxygen, fluorescence, and turbidity. A microstructure probe (MicroRider, s/n 38, Rockland Scientific) was mounted to the top of the glider. Two shear and two fast thermistor sensors were attached to the tip of the MicroRider. During the mission, the sampling rate of velocity, pressure, pitch and roll, and temperature was $64 \mathrm{~Hz}$, while shear, temperature gradient, and accelerometer data were sampled at $512 \mathrm{~Hz}$. The glider dove to $900 \mathrm{~m}$ depth and surfaced after each dive for data transmission. We use 108 microstructure profiles collected during the upcasts and downcasts.

Standard postprocessing procedures were applied to determine dissipation rates of turbulent kinetic energy $\left(\epsilon, \mathrm{m}^{2} \mathrm{~s}^{-3}\right)$ from the microstructure shear data (e.g., Fer et al., 2014; Schafstall et al., 2010). Glider velocity 
was determined using a dynamic flight model, which was shown to contribute only minorly to uncertainty in $\epsilon$ (Merckelbach et al., 2019). Estimates of $\epsilon$ were derived by integrating shear spectra from 1,024 data points assuming isotropic turbulence while correcting for the shear probe's spatial response (e.g., Fer et al., 2014). We did not apply a Goodman-filter (Goodman et al., 2006) that removes shear data coherent with the MicroRider's accelerometer readings. However, careful editing for outliers was necessary to exclude data spikes originating mainly from collisions of the shear sensors with small particles predominately in the deep chlorophyll layer. Finally, turbulent diffusivities $\left(K_{v}\right)$ were calculated from $\epsilon$ and the square of the buoyancy frequency, $N^{2}=-g / \rho_{o} \partial \rho / \partial z$, using $K_{v}=\Gamma \epsilon / N^{2}$ (Osborn, 1980) and $\Gamma=0.2$. Because of the limited duration of the glider measurements, they are used mainly to validate the model results at $4^{\circ} \mathrm{N}$ (see section 2.4 ).

\subsection{Ocean Temperature, Surface Heat Flux, and Reanalysis Data}

We use three gridded data sets to determine the spatial distribution of the mixed layer heat budget residual and near-surface winds shown in Figure 1, providing context for our results at fixed mooring locations. For this residual calculation, we omit horizontal advection because of large uncertainties in horizontal mixed layer velocity from satellite-based and reanalysis products (Foltz et al., 2018). The mixed layer heat storage rate is calculated using monthly microwave-infrared satellite SST and MLD based on monthly EN4.2.1 temperature and salinity (Good et al., 2013; https://www.metoffice.gov.uk/hadobs/en4/download-en4-2-1. $\mathrm{html})$. For this calculation and the analysis of glider data, we calculate MLD using the criterion of a $0.12 \mathrm{~kg} \mathrm{~m}^{-3}$ increase in density from a depth of $5 \mathrm{~m}$, the uppermost level available. The surface heat flux consists of latent, sensible, longwave, and shortwave components and is obtained from the TropFlux monthly data set along with near-surface wind velocity (Kumar et al., 2012; http://www.incois.gov.in/tropflux/). We use an albedo of $6 \%$ and calculate the amount of shortwave radiation absorbed in the mixed layer as $Q_{\mathrm{abs}}=Q_{\mathrm{sfc}}\left(1-0.47 e^{-h / 15}\right)$, where $Q_{\mathrm{sfc}}$ is the net surface shortwave radiation and $h$ is MLD in meters (Foltz et al., 2003; Wang \& McPhaden, 1999). All terms are calculated for the period 2003-2017 and then averaged to monthly climatologies on a $1^{\circ}$ grid.

\subsection{Mixing Parameterizations and Calculation of the Vertical Turbulent Heat Flux at $4^{\circ} \mathrm{N}$} 2.4.1. KPP

At $4^{\circ} \mathrm{N}$ we calculate $K_{v}$ using the ocean interior portion of the K-profile parameterization (KPP; Large et al., 1994; Smyth et al., 2002). The model represents turbulent mixing as the sum of a background diffusivity of $10^{-5} \mathrm{~m}^{2} \mathrm{~s}^{-1}$ and shear-induced mixing based on the local gradient Richardson number, $R i=N^{2} / S^{2}$, where $S^{2}=(\partial u / \partial z)^{2}+(\partial v / \partial z)^{2}$ is the square of the vertical shear of the horizontal velocity, $u$ is zonal velocity, and $v$ is meridional velocity. Here we set the background diffusivity to zero because our direct measurements of velocity include processes such as internal waves that ocean circulation models do not resolve well. $K_{v}$ increases above zero as Ri decreases below a critical value, $R i_{0}$. For $0<R i<R i_{0}$ it is parameterized as

$$
K_{v}=K_{v}^{0}\left[1-\left(\frac{R i}{R i_{0}}\right)^{2}\right]^{3}
$$

where $K_{v}^{0}=5 \times 10^{-3} \mathrm{~m}^{2} \mathrm{~s}^{-1}$ (Smyth et al., 2002). Large et al. (1994) set $R i_{0}=0.7$. Here we use a lower value of $R i_{0}=0.45$ because we have direct measurements of hourly velocity shear and stratification. The specific value of 0.45 was chosen to match that in a different parameterization used to validate KPP (described below). Table 1 summarizes the KPP setup.

\subsubsection{KWB}

In addition to KPP, we apply the parameterization of Kunze et al. (1990), hereafter KWB, to the hourly data at $4^{\circ} \mathrm{N}$. The turbulent dissipation rate is given as

$$
\epsilon=\frac{\Delta z^{2}}{96}\left\langle S^{2}-\frac{N^{2}}{R i_{c}}\right\rangle\left\langle S-\frac{N}{\sqrt{R i_{c}}}\right\rangle
$$

where $\Delta z$ is the vertical resolution at which $N$ and $S=\sqrt{S^{2}}$ are calculated, and the quantities in brackets are set to zero if they are less than zero (i.e., $R i>R i_{c}$; Kunze et al., 1990; Peters et al., 1995; Polzin, 1996; Wenegrat $\&$ McPhaden, 2015). Here we set $R i_{c}=0.45$, which gives the best fit to observations for our vertical spacing of 5-10 m (Polzin, 1996). From $\epsilon$ we calculate diffusivity as described in section 2.2: $K_{v}=\Gamma \epsilon / N^{2}$. 
Table 1

Details of the Mixing Parameterizations and Model Experiments at $4^{\circ} \mathrm{N}, 23^{\circ} \mathrm{W}$ and $15^{\circ} \mathrm{N}, 38^{\circ} \mathrm{W}$

\begin{tabular}{|c|c|c|}
\hline & $4^{\circ} \mathrm{N}, 23^{\circ} \mathrm{W}$ & $15^{\circ} \mathrm{N}, 38^{\circ} \mathrm{W}$ \\
\hline Parameterization/model & KPP, KWB & PWP \\
\hline Time period & $\begin{array}{c}\text { March } 2017 \text { to March } 2018 \\
\text { May-October } 2019\end{array}$ & 2001-2003, 2006, 2007, 2012 \\
\hline Input/forcing & Hourly $T(z), S(z), v(z)$ & $\begin{array}{c}\text { Hourly shortwave } \\
\text { Daily winds, latent, sensible, } \\
\text { longwave, } E-P\end{array}$ \\
\hline Initialization & None (parameterization) & $\begin{array}{c}\text { Daily ePIRATA } T(z), S(z) \\
\text { at beginning of each month }\end{array}$ \\
\hline Output & Vertical diffusivity $\left(K_{v}\right)$ & $T(z), S(z), v(z)$ \\
\hline Experiments & $\begin{array}{c}\text { CONTROL } \\
T I W_{\text {rem }}, N I W_{\text {rem }}, H F V_{\text {rem }}\end{array}$ & $\begin{array}{c}\text { CONTROL } \\
\text { Daily mean shortwave }\end{array}$ \\
\hline
\end{tabular}

\subsubsection{Validation of KPP and KWB}

The glider microstructure measurements acquired during 30 October to 6 November 2012 near $5^{\circ} \mathrm{N}, 23^{\circ} \mathrm{W}$ provide an opportunity to evaluate the performances of the KPP and KWB parameterizations. Hourly mooring data during 17 October to 15 November 2017 are used for this comparison. Because the mooring data and microstructure observations were obtained during different years and the microstructure observations cover only one week, a detailed comparison cannot be made. Instead, we compare the statistics of the observed and modeled diffusivities beneath the mixed layer.

The parameterizations appear to overestimate diffusivity between the MLD and $30 \mathrm{~m}$ below the mixed layer (Figure 3). Averaged between the MLD and $2 \mathrm{~m}$ below the mixed layer, the mean diffusivities from KPP and KWB are $1.5 \times 10^{-4} \mathrm{~m}^{2} \mathrm{~s}^{-1}$ and $8.8 \times 10^{-5} \mathrm{~m}^{2} \mathrm{~s}^{-1}$, respectively, compared to $1.5 \times 10^{-5} \mathrm{~m}^{2} \mathrm{~s}^{-1}$ based on microstructure measurements. The parameterizations also have higher percentages of large diffusivities ( $>5 \times 10^{-5} \mathrm{~m}^{2} \mathrm{~s}^{-1}$ ) between the MLD and $2 \mathrm{~m}$ below the mixed layer: $15 \%$ and $13 \%$ for KPP and KWB, respectively, and $3 \%$ for microstructure. To balance these larger values, the parameterizations have higher percentages of very low diffusivity values $\left(<10^{-8} \mathrm{~m}^{2} \mathrm{~s}^{-1}\right.$, not shown in Figures $3 \mathrm{a}$ and $\left.3 \mathrm{~b}\right) 0-2 \mathrm{~m}$ below the mixed layer: $80 \%$ and $79 \%$ for KPP and KWB, respectively. These small diffusivities are almost never observed (Figure 3c) because they are within the noise level of the instrument. Based on the similarities between the diffusivities from KPP and KWB, in the remainder of the paper we show results only for KPP except to compare KPP- and KWB-derived monthly mean turbulent heat fluxes in section 3.1.

\subsubsection{Calculation of the Vertical Turbulent Heat Flux}

At $4^{\circ} \mathrm{N}$, vertical turbulent cooling of the mixed layer is calculated using the vertical profiles of $K_{v}$ from the KPP parameterization and profiles of temperature and salinity from the mooring. First, from hourly temperature and salinity we define the MLD as the shallowest depth at which density is $0.12 \mathrm{~kg} \mathrm{~m}^{-3}$ greater than the value at a depth of $1 \mathrm{~m}$. The vertical turbulent heat flux is then calculated as $Q_{h}=-\rho c_{p} K_{v} \partial T / \partial z$, where $T$ is ocean temperature, $K_{v}$ is evaluated at the base of the mixed layer, and $\partial T / \partial z$ is calculated between the MLD and $10 \mathrm{~m}$ below the mixed layer.

We perform several experiments with KPP. To test the impact of high-frequency (periods less than 2 days) variations of temperature and current shear on mixing, we average temperature, salinity, and velocity to daily means before running the KPP model (experiment $\mathrm{HFV}_{\text {rem}}$, where "rem" stands for "removed"). To look at the impact of NIWs, we remove 5.5-9 day band-pass filtered temperature, salinity, and velocity at each depth from the full time series (experiment NIW $_{\text {rem }}$ ). Similarly, we remove 20-50 day band-pass filtered time series to investigate the contribution from TIWs $\left(\mathrm{TIW}_{\text {rem }}\right)$, consistent with the method used in Perez et al. (2012). The experiments are summarized in Table 1. 

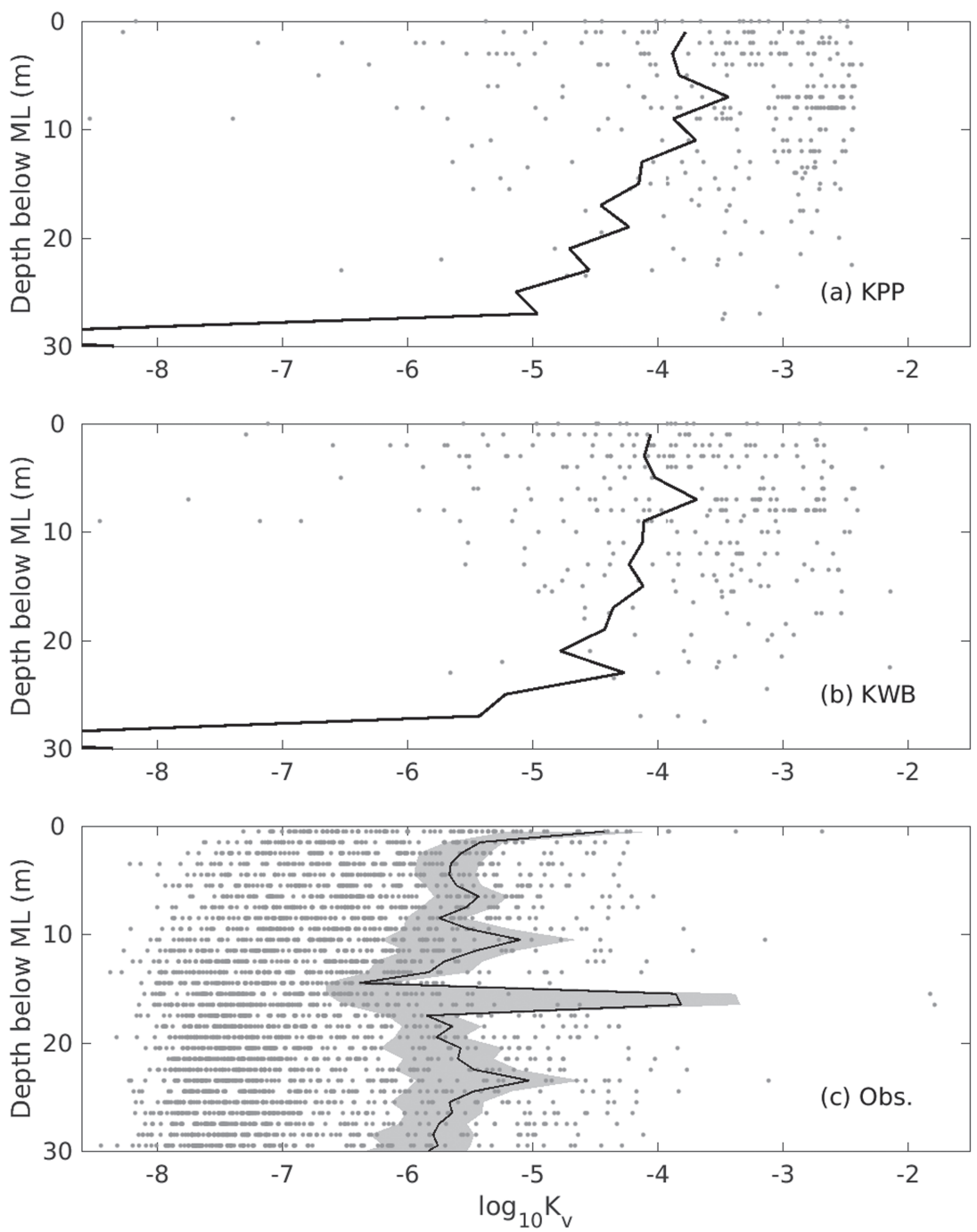

Figure 3. Vertical eddy diffusivity below the mixed layer from mixing parameterizations and microstructure observations. (a) KPP during 17 October to 15 November 2017. (b) KWB during 17 October to 15 November 2017. (c) Microstructure during 30 October to 6 November 2012. Dots show hourly data from the parameterizations and individual microstructure profiles. Black lines are averages at each depth. Gray shading in (c) indicates the $95 \%$ confidence level based on a bootstrap technique (Schafstall et al., 2010).

\subsection{One-Dimensional MLD and Calculation of the Vertical Turbulent Heat Flux at $15^{\circ} \mathrm{N}$}

At $15^{\circ} \mathrm{N}$, in contrast to $4^{\circ} \mathrm{N}$, we do not have direct measurements of current shear from which to calculate diffusivity and the turbulent heat flux. We therefore rely on the Price-Weller-Pinkel (PWP) model (Price et al., 1986) to provide time series of ocean temperature, from which the vertical turbulent heat flux at the base of the mixed layer can be inferred using the heat budget residual technique. There are several reasons for using PWP to estimate vertical turbulent cooling. First, PWP provides an estimate that is, to a large extent, independent of that obtained from the mooring heat budget residual, since PWP calculates its own ocean temperature, salinity, velocity, and mixing. In addition, the higher vertical resolution of PWP compared to the mooring allows PWP to resolve the diurnal cycle much better, and with PWP we can perform experiments to isolate the importance of the diurnal cycle for vertical turbulent cooling.

\subsubsection{Model Setup}

We use hourly shortwave radiation directly from the mooring and daily wind stress, latent, sensible, and longwave heat fluxes, and evaporation minus precipitation $(E-P)$ from ePIRATA to force the PWP model. We found that results are essentially the same if we use hourly winds, latent, sensible, longwave, and $E-P$ instead of daily. Using hourly shortwave and daily averages of the other forcing terms allows us to run the model over a longer period of time, since there are more gaps in the hourly records. At each time step, solar 

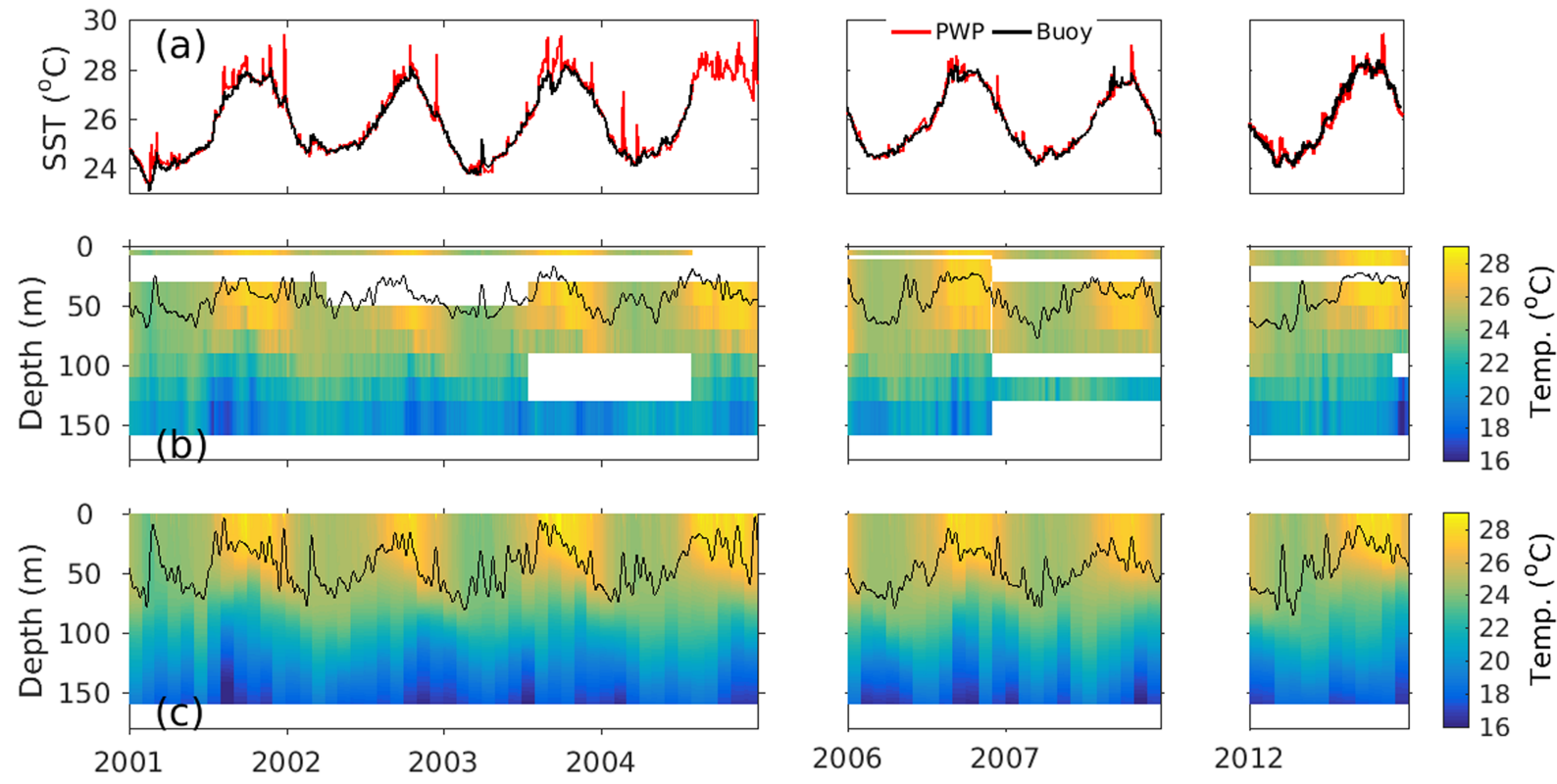

Figure 4. Ocean temperature from the $15^{\circ} \mathrm{N}, 38^{\circ} \mathrm{W}$ PIRATA mooring and the PWP model. (a) SST. Temperature (shaded) and mixed layer depth (black line) from (b) the mooring and (c) PWP. White shading in (b) indicates missing data from one or more sensors.

radiation is absorbed with a double exponential depth dependence (Kraus, 1972; Paulson \& Simpson, 1977) and the surface heat and moisture fluxes are applied to the top grid level (i.e., the surface). The density profile is then adjusted to achieve static stability. Wind stress is absorbed in the mixed layer and entrainment occurs until the bulk Richardson number, $R i_{b}=\frac{g \Delta \rho h}{\rho_{o}(\Delta \mathbf{v})^{2}}$ is greater than 0.65 . Here $\Delta \rho$ and $\Delta \mathbf{v}$ are differences of density and velocity, respectively, between the mixed layer and immediately beneath. Mixing of adjacent vertical grid levels is then carried out until $R i$ (the gradient Richardson number) is greater than 0.25 .

At the beginning of each month of each year (2001-2004, 2006, 2007, and 2012), we initialize the model with temperature and salinity from ePIRATA at $15^{\circ} \mathrm{N}$. These initial temperature and salinity profiles are averaged over the 5 days prior to the start of each month, then the model is run for 1 month using a time increment of $15 \mathrm{~min}$ and a vertical resolution of $1 \mathrm{~m}$. A similar methodology was used by Rugg et al. (2016). This gives 84 different 1-month model runs (12 months from each of 7 years) with temperature, salinity, and velocity in the upper $200 \mathrm{~m}$. The advantage of this technique is that it ensures that the modeled temperature does not drift far from the observations (Figures 4, 5a, and 5b). Table 1 summarizes the model setup.

The seasonal cycles of SST standard deviation (SD) from the model and the mooring, calculated using only periods when data from both are available, show maxima in July-August and December-February (solid lines in Figure 5a). The model overestimates SST variability on time scales of $\sim 3-6$ days during August-December (Figure 4a), causing the monthly variances to be too high (Figure 5a). However, diurnal SST variance is very well simulated by the model (compare dashed lines in Figure 5a). At depths of 40 and $60 \mathrm{~m}$ the model's temperature variance agrees well with the mooring's during January-May but underestimates it during June-December (Figure 5b). The underestimation is most pronounced in the thermocline, which is located near $40 \mathrm{~m}$ in September and $60 \mathrm{~m}$ in November-December. This is likely due to the lack of remotely generated signals, such as internal waves, in the PWP model.

The model underestimates velocity variance at a depth of $10 \mathrm{~m}$ compared to direct measurements from the mooring (Figures $5 \mathrm{c}$ and $5 \mathrm{~d}$ ). This is also likely due to the absence of remotely generated waves and currents in the model. Indeed, the underestimation is most pronounced for superinertial frequencies (periods less than about 1.5 days), with monthly variances at $10 \mathrm{~m}$ depth in the model that are a factor of 3-12 lower compared to direct measurements from the mooring (not shown). This is not surprising because the model is forced only by local winds. When all frequencies are included, the model's velocity variance is about a factor of 5 too low and the seasonality is too weak (compare solid lines in Figures $5 \mathrm{c}$ and $5 \mathrm{~d}$ ). The large peak in inertial velocity variance present in the mooring data is also much weaker in the model (dashed lines 

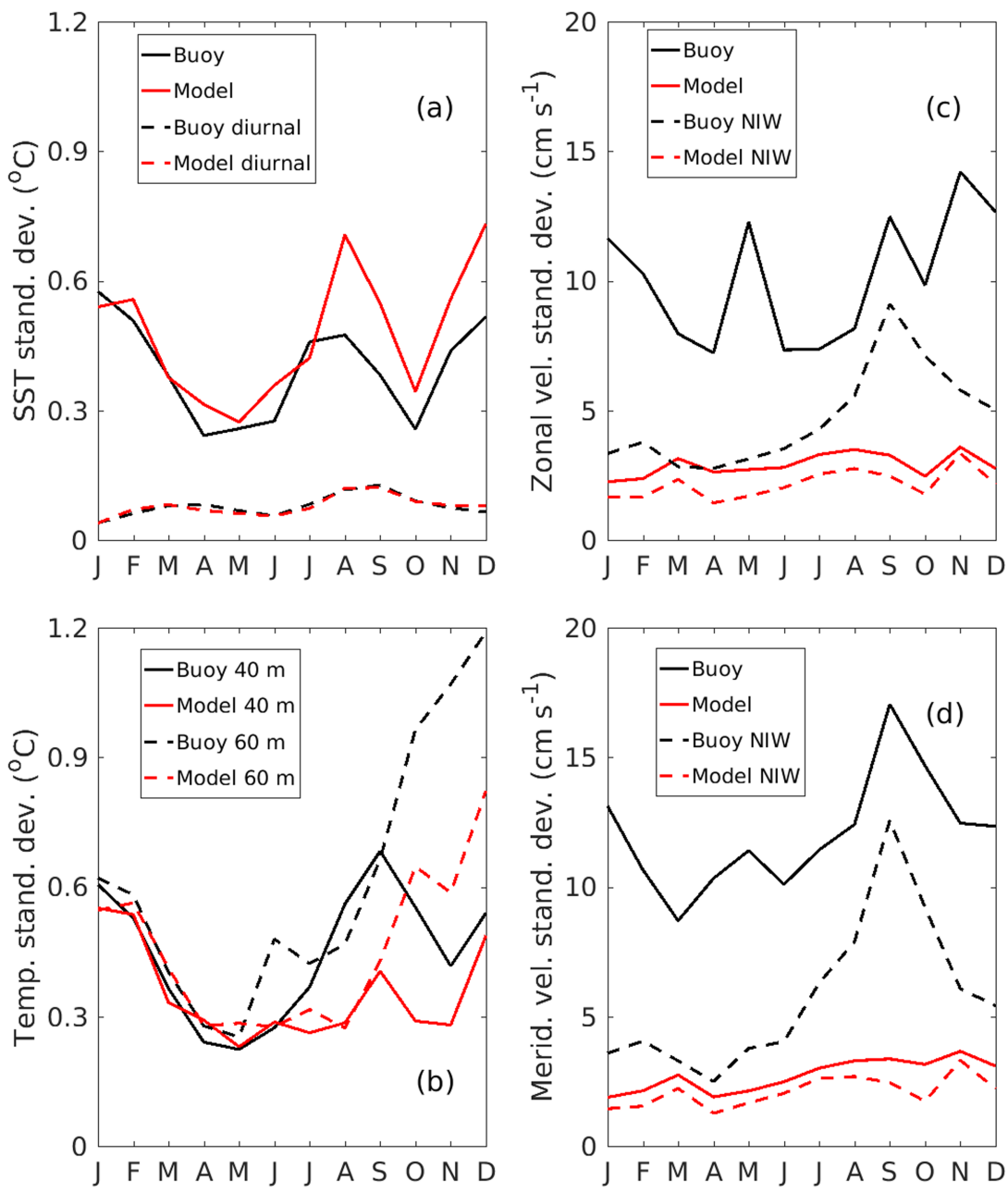

Figure 5. Comparison of temperature and velocity from the $15^{\circ} \mathrm{N}, 38^{\circ} \mathrm{W}$ buoy and from PWP. Shown are monthly standard deviations for each calendar month. (a) SST (solid) and diurnal (12-36 hr band-pass filtered) SST (dashed). (b) Temperature at a depth of 40 (solid) and $60 \mathrm{~m}$ (dashed). (c) Zonal velocity at a depth of $10 \mathrm{~m}$ (solid) and near-inertial wave (1.5-2.5 day band-pass filtered) zonal velocity (dashed). (d) Same as (c) but for meridional velocity.

in Figures $5 \mathrm{c}$ and $5 \mathrm{~d}$ ). Because of the limitations of the PWP model at $15^{\circ} \mathrm{N}$, these experiments are used mainly to test the extent to which direct wind and buoyancy forcing contribute to turbulent cooling of the mixed layer. In contrast, at $4^{\circ} \mathrm{N}$ the full oceanic conditions are more realistically represented by the direct measurements from the mooring that include velocity shear, and the use of the PWP model is not required.

\subsubsection{Calculation of the Vertical Turbulent Heat Flux}

At $15^{\circ} \mathrm{N}$ we calculate vertical turbulent cooling as the residual in the PWP mixed layer heat balance since the model does not generate a vertical eddy diffusivity:

$$
R_{\mathrm{PWP}_{t}}=\rho c_{p} \frac{h_{t}+h_{t+1}}{2} \frac{\bar{T}_{t+1}-\bar{T}_{t}}{\Delta t}-Q_{t}
$$

Here the subscript $t$ refers to the model time step, $\Delta t=15 \mathrm{~min}, h$ is MLD calculated using the criterion of an increase in density of $0.12 \mathrm{~kg} \mathrm{~m}^{-3}$ from a depth of $1 \mathrm{~m}$, and $Q_{t}$ is the surface heat flux after accounting for solar radiation that penetrates through the base of the mixed layer. Horizontal heat advection is zero because the model is one-dimensional. To estimate the impact of the diurnal cycle on mixing and turbulent cooling at $15^{\circ} \mathrm{N}$ we calculate the difference in $R_{\mathrm{PWP}}$ between the model control run with forcing from hourly solar radiation and a run with daily solar radiation (see Table 1). 

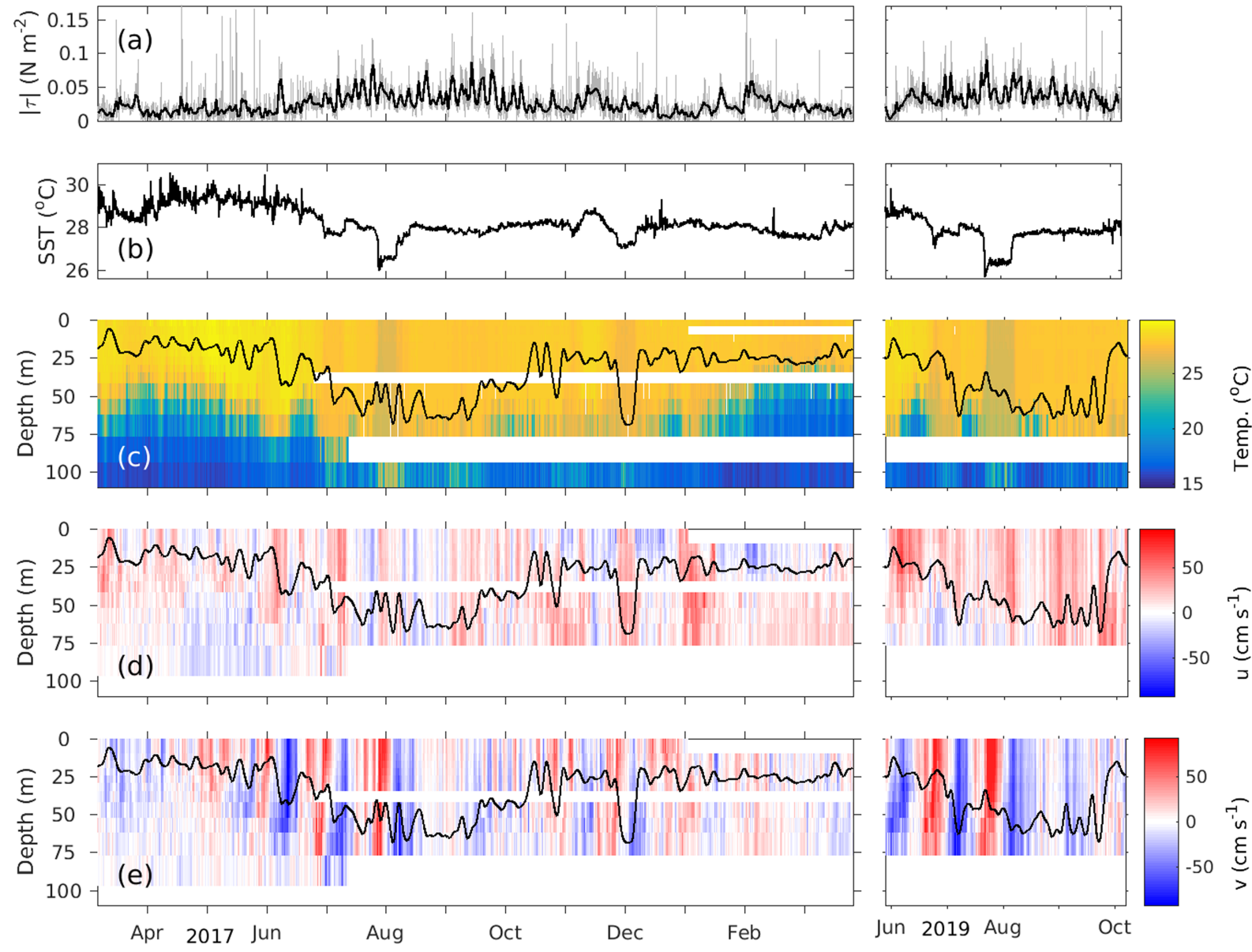

Figure 6. Measurements from the $4^{\circ} \mathrm{N}, 23^{\circ} \mathrm{W}$ mooring. (a) Hourly (gray) and daily (black) wind stress magnitude, (b) SST, (c) temperature, (d) zonal velocity, and (e) meridional velocity. Black line in panels (c)-(e) is the mixed layer depth, smoothed with a 5-day low-pass filter.

\section{Results}

\subsection{ITCZ Region: $4^{\circ} \mathrm{N}, 23^{\circ} \mathrm{W}$}

3.1.1. Observed Seasonal and Higher-Frequency Variability

At $4^{\circ} \mathrm{N}$ surface winds are weakest during boreal winter and spring, when the core of the ITCZ is located between the equator and $5^{\circ} \mathrm{N}$ (Chiang et al., 2002). When the ITCZ moves northward during boreal summer, winds increase, MLD increases, and SST decreases from 29 to $28^{\circ} \mathrm{C}$ (Figures 6a-6c). There are strong meridional and weaker zonal velocity fluctuations from TIWs during June-August in 2017 and 2019 and to a lesser extent during October-December 2017 (Figures 6d and 6e). Below the mixed layer, stratification tends to be strongest during boreal winter and spring, when the mixed layer is thinnest (Figure 7a). Shear is generally largest below the mixed layer and becomes very small when the mixed layer is thickest in August-September (Figure 7b). To assess the likelihood of mixing, we consider the reduced $S^{2}: S_{\text {red }}^{2}=S^{2}-4 N^{2}$ (Kunze et al., 1990; Wenegrat \& McPhaden, 2015). When $S_{\text {red }}^{2}>0, R i<0.25$ and the flow is more likely to be unstable. Near the base of the mixed layer, $S_{\text {red }}^{2}>0$ is most often found during May-July (pink shading in Figure 7c), when the MLD is increasing and TIWs are active.

Stratification at the base of the mixed layer (hereafter $N_{h}^{2}$ ) does not have a strong seasonality and instead is dominated by intraseasonal fluctuations during July-August 2017 and 2019 and higher-frequency variations throughout the year (Figure 8a). In contrast, there is a seasonal minimum in $S^{2}$ at the base of the mixed layer (hereafter $S_{h}^{2}$ ) during August-September 2017 and 2019 as well as strong higher-frequency variability throughout the year (Figure $8 \mathrm{~b}$ ). There is consistently high stability $\left(S_{\text {red }}^{2}<0\right)$ at the base of the mixed layer during mid-February through March 2018 and mid-August through September of both years. The likelihood of instability is greater during the TIW season (May through early August) and also in October 2017 through mid-February 2018, when $S_{\text {red }}^{2}$ occasionally becomes positive (Figure 8c). As a result, the largest $K_{v}$ at the base 

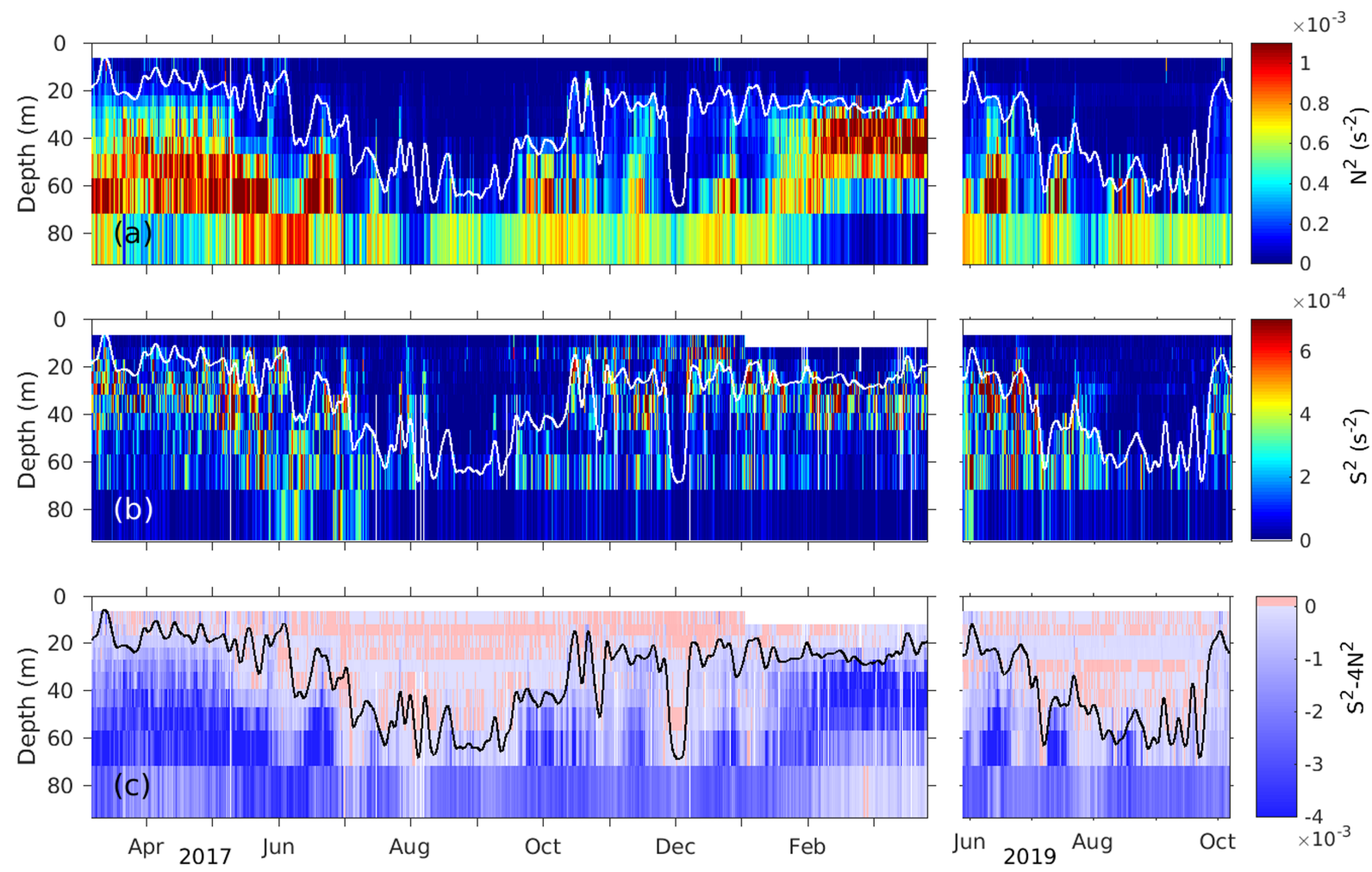

Figure 7. Stratification, shear, and stability at $4^{\circ} \mathrm{N}$. (a) $N^{2}(-\mathrm{g} / \rho 0 \partial \rho / \partial \mathrm{z})$, (b) velocity shear squared $\left(S^{2}\right)$, and (c) reduced $S^{2}$. White lines in panels (a) and (b) and black line in panel (c) show the mixed layer depth.

of the mixed layer (hereafter $K_{v h}$ ) and strongest turbulent heat flux at the base of the mixed layer (hereafter $Q_{h}$, with negative values representing cooling) occur during May-July and November-January (Figures 8d and 8e).

The results in Figures 7 and 8 suggest that seasonal changes in MLD may affect $S_{h}^{2}, K_{v h}$, and $Q_{h}$, with a thinner mixed layer in December-May associated with stronger mixing and more turbulent cooling on average. A thinner mixed layer is more responsive to surface wind and buoyancy forcing, possibly allowing a given wind stress or buoyancy flux to induce stronger shear and more mixed layer deepening. During December-May, when the mean MLD is $21 \mathrm{~m}$, the correlation between MLD and $S_{h}^{2}$ is 0.24 , indicating that deepening of the mixed layer is associated with larger $S_{h}^{2}$. This stronger shear generates more mixing, supported by a correlation between MLD and $Q_{h}$ of -0.14 . Both correlations are significant at the $99 \%$ level. In contrast, during August-September, when the mixed layer is $54 \mathrm{~m}$ thick on average, $S_{h}^{2}$ tends to be smaller when the mixed layer is thicker (correlation of -0.52).

\subsubsection{Diurnal, NIW, and TIW Composites}

To examine higher-frequency variability in more detail, we first focus on March-April 2017, when winds are weak, diurnal variations of SST are strong, and NIWs are present (Figure 9). The diurnal amplitude of SST reaches up to $1.5^{\circ} \mathrm{C}$ during some days in April, and the mixed layer shoals to less than $10 \mathrm{~m}$ during warm phases of the diurnal cycle (Figures $9 \mathrm{a}$ and $9 \mathrm{~b}$ ). NIWs with amplitudes of $30-40 \mathrm{~cm} \mathrm{~s}^{-1}$ are evident in both components of velocity (Figures 9c and 9d), and there are periods with enhanced $S^{2}$ near the base of the mixed layer, especially during 3-4 and 9-12 April (Figure 9e). There are also semidiurnal fluctuations that are most visible in the meridional component of velocity and are likely due to tides, though they are weaker than the NIWs.

To investigate the potential impacts of the diurnal cycle, NIWs, and TIWs on stratification, shear, and mixing, we perform composite analyses. For the diurnal cycle, we use data from March-June 2017 and May-September 2019, when direct measurements of SST at a depth of $1 \mathrm{~m}$ are available from the mooring. We first smooth hourly wind speed with an 11-day running mean and then form hourly diurnal 

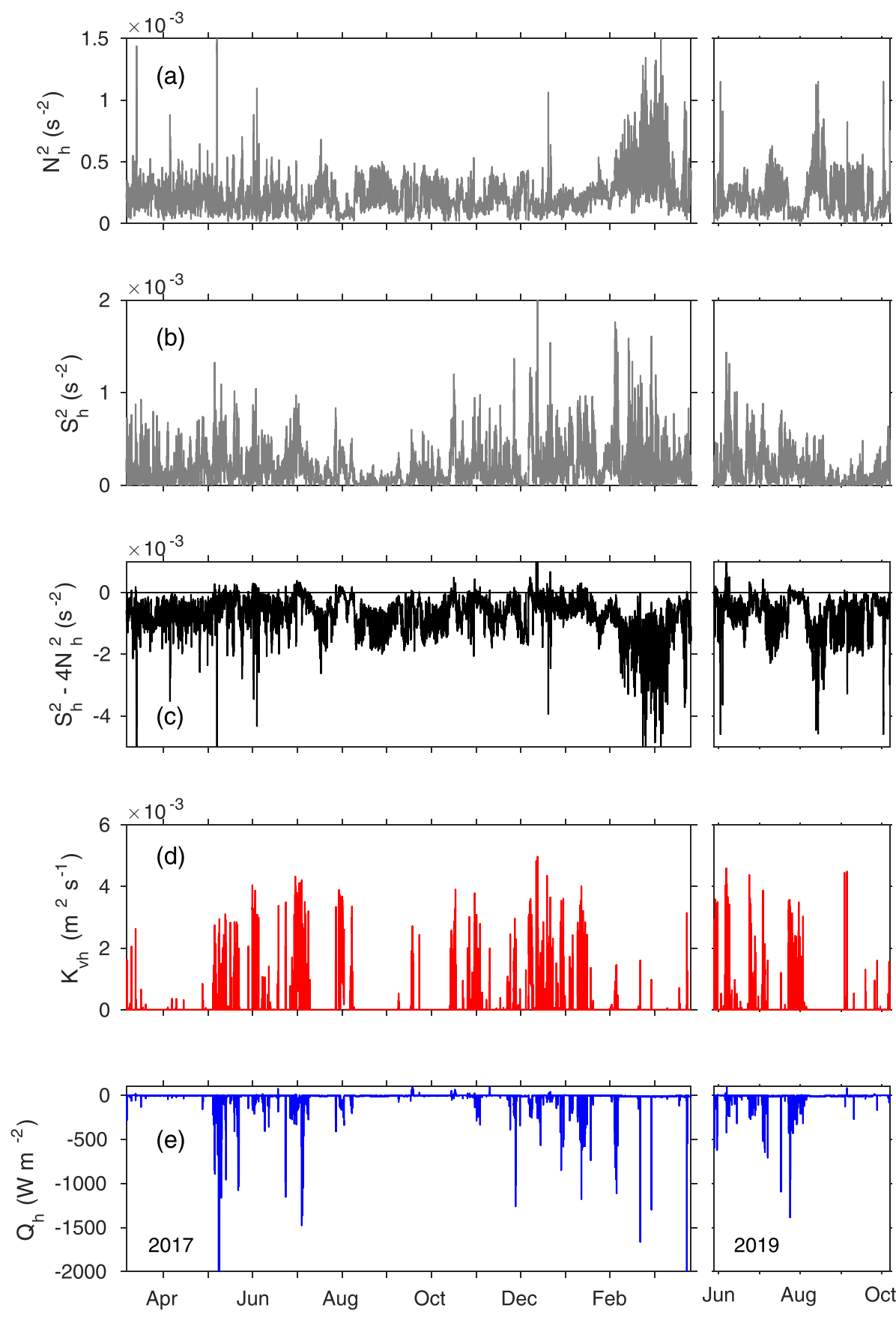

Figure 8. Conditions at the base of the mixed layer at $4^{\circ}$ N. (a) $N^{2}$, (b) $S^{2}$, (c) reduced $S^{2}$, (d) eddy diffusivity, and (e) vertical turbulent heat flux.

composites using data only when the smoothed wind speed is less than $3 \mathrm{~m} \mathrm{~s}^{-1}$ (magenta lines in Figure 10a). Gentemann et al. (2003) show that the diurnal cycle of SST is strongest for wind speeds below this threshold.

The diurnal SST composite shows a maximum during 15:00-17:00 local time that is about $0.4{ }^{\circ} \mathrm{C}$ warmer than the nighttime minimum (Figure 10b). Note that this composite diurnal amplitude is considerably smaller than the maximum amplitudes observed on individual days (Figure 9a). The peak in the diurnal composite of SST is associated with a minimum in MLD. Near-surface zonal velocity, measured at a depth of $7 \mathrm{~m}$, peaks around noon, and there is not a clear diurnal cycle in meridional velocity (Figure 10c). However, $S_{h}^{2}$ is largest at night and decreases rapidly between 8:00 and 10:00 as SST increases and MLD shoals (Figure 10d). This indicates that diurnally varying currents do not have a significant impact on $S_{h}^{2}$. Instead, 

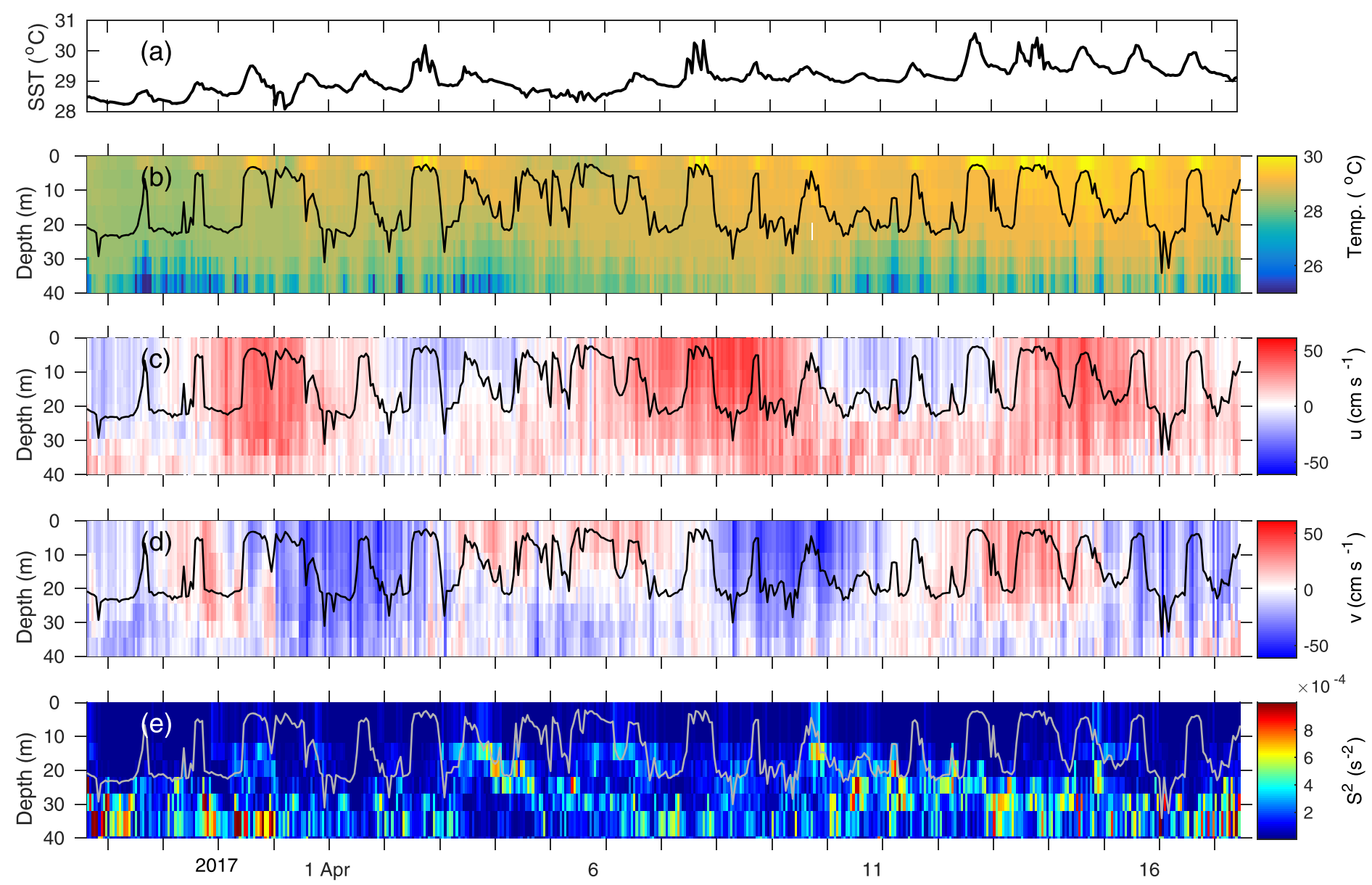

Figure 9. Measurements from the $4^{\circ} \mathrm{N}$ mooring during March-April 2017. (a) SST, (b) temperature, (c) zonal velocity, (d) meridional velocity, and (e) $S^{2}$. Black lines in panels (a)-(d) and gray line in panel (e) indicate the mixed layer depth.

$S_{h}^{2}$ increases as the mixed layer thickens and extends into the region with higher $S^{2}$ in the upper thermocline (Figures 7a, 7b, and 9e). $N_{h}^{2}$ tends to be largest between 12:00 and 18:00, but its diurnal cycle is less pronounced than $S_{h}^{2}$. Not surprisingly, $K_{v}$ tends to be largest and $Q_{h}$ strongest during the night and early morning, when $S_{h}^{2}$ is largest and $N_{h}^{2}$ is weakest (Figure 10e).

Despite significant diurnal variations of $S_{h}^{2}$ and mixing, the diurnal cycle does not appear to have a large impact on the annual mean or seasonal cycle of $Q_{h}$. During periods with wind speed less than $3 \mathrm{~m} \mathrm{~s}^{-1}$, the mean $Q_{h}$ is $-21 \mathrm{~W} \mathrm{~m}^{-2}$, compared to $-20 \mathrm{~W} \mathrm{~m}^{-2}$ for wind speed greater than $3 \mathrm{~m} \mathrm{~s}^{-1}$. These calculations were performed during March-May 2017, when the mean MLD and SST are similar, though results are similar when other time periods are considered.

In contrast, there are significant differences in the mean state during periods with high- and low-NIW energy. Here we define periods of high-NIW energy as those for which the 5.5-9 day band-pass filtered $u^{2}+v^{2}$ at a depth of $7 \mathrm{~m}$ is greater than $1 \mathrm{SD}(\sigma)$ above its mean $(\mu)$ (Figure 11a). Low-NIW energy is defined as less than the mean energy minus $75 \%$ of the SD (i.e., $\mu-0.75 \sigma$ ). On average, when there are strong NIWs, the mixed layer is thinner, stratification is weaker, $S_{h}^{2}$ is stronger, $K_{v}$ is higher, and cooling from $Q_{h}$ is larger (Figure 11b). These results contrast with those of the diurnal cycle, which show that a thinner mixed layer is associated with weaker $S_{h}^{2}$, smaller $K_{v}$, and reduced cooling from $Q_{h}$. The difference may be related to the preference for stronger NIWs to occur when the mixed layer is thin, possibly due to stronger sensitivity of near-surface currents to wind forcing (e.g., D'Asaro, 1985). However, the diurnal cycle is strongest when winds are weak so that the afternoon minimum in MLD does not result in significantly enhanced shear. Results for NIWs are similar when currents at other depths such as 17 and $27 \mathrm{~m}$ are used to define NIW 

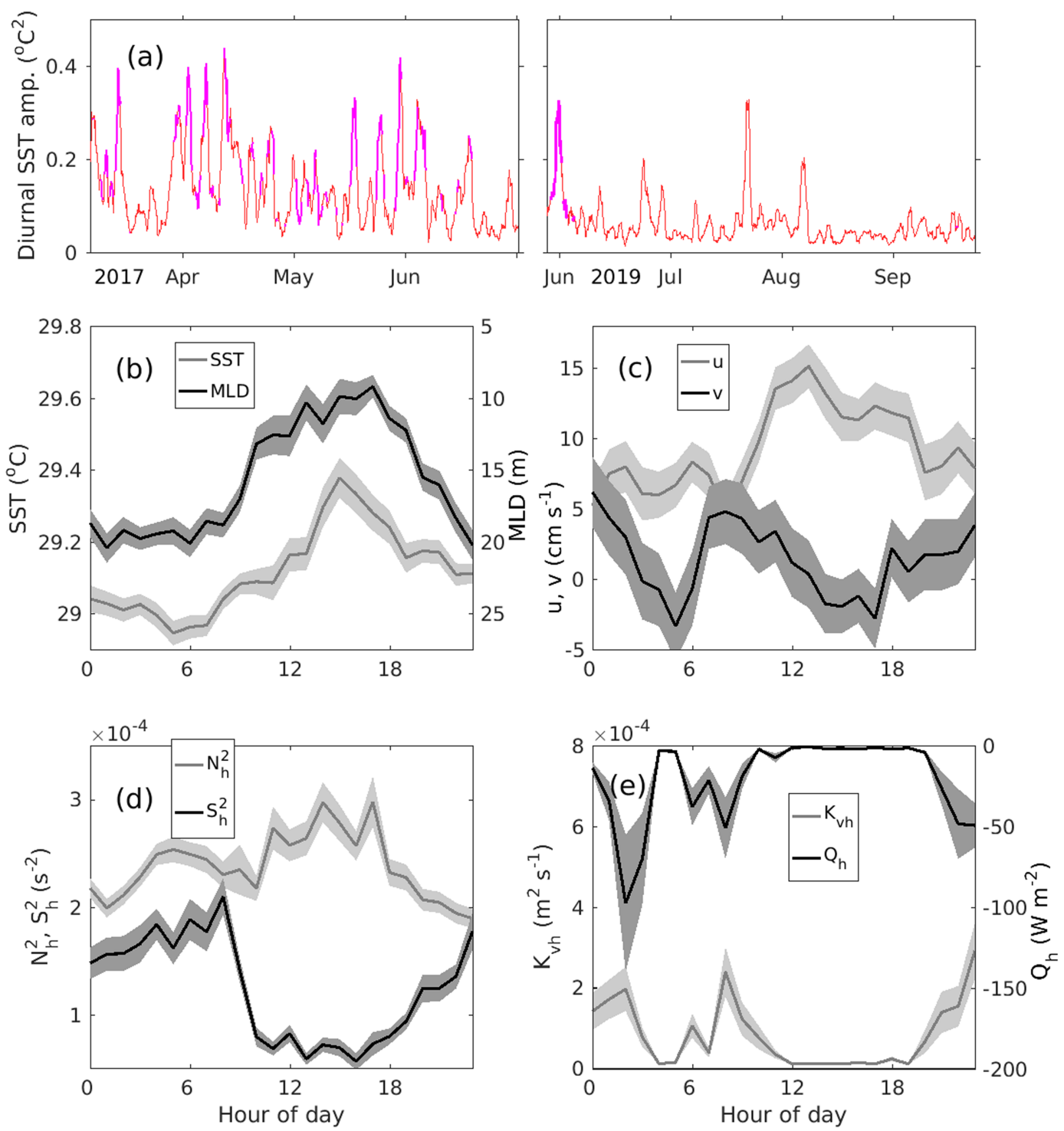

Figure 10. Diurnal variability at $4^{\circ} \mathrm{N}$. (a) Diurnal SST amplitude, defined as the square of each hourly value relative to the daily mean (red), and hours identified as having a strong diurnal cycle (magenta). Diurnal composites, based on periods identified in magenta in (a), of (b) mixed layer depth and SST, (c) zonal and meridional velocity at a depth of 7 $\mathrm{m},(\mathrm{d}) N^{2}$ and $S^{2}$ at the base of the mixed layer, and (e) diffusivity and vertical turbulent heat flux at the base of the mixed layer.

energy. However, at deeper levels the NIW energy signal becomes much weaker and the differences between the high- and low-NIW energy composites are smaller.

To examine the impact of TIWs on mixing we used a similar methodology. The TIW energy is defined as the 20-50 day band-pass filtered $u^{2}+v^{2}$ at a depth of $7 \mathrm{~m}$. High-TIW energy is defined as $>1$ SD above the mean, and low-TIW energy is defined as less than the mean minus $40 \%$ of the SD (Figure 12a). The mean differences in MLD and stratification between high-TIW energy and low-TIW energy periods are small, but there are large differences in $S_{h}^{2}, K_{v}$, and $Q_{h}$ (Figure 12b). TIWs generate stronger $S_{h}^{2}$, larger $K_{v}$, and stronger cooling from $Q_{h}$. On average, $Q_{h}$ is $38 \mathrm{~W} \mathrm{~m}^{-2}$ during periods with strong TIWs and $19 \mathrm{~W} \mathrm{~m}^{-2}$ during periods without TIWs, a difference that is significant at the $99 \%$ level.

\subsubsection{Seasonal Cycle of Turbulent Cooling and Comparison to Heat Budget Residual}

The monthly mean time series of $Q_{h}$, calculated from the KPP $K_{v}$ and the mooring $\partial T / \partial t$, show strongest cooling during May-July and weakest cooling in August-October and March-April (solid black and red curves in Figure 13a). There is generally good agreement between $Q_{h}$ estimated from KPP and KWB in terms 

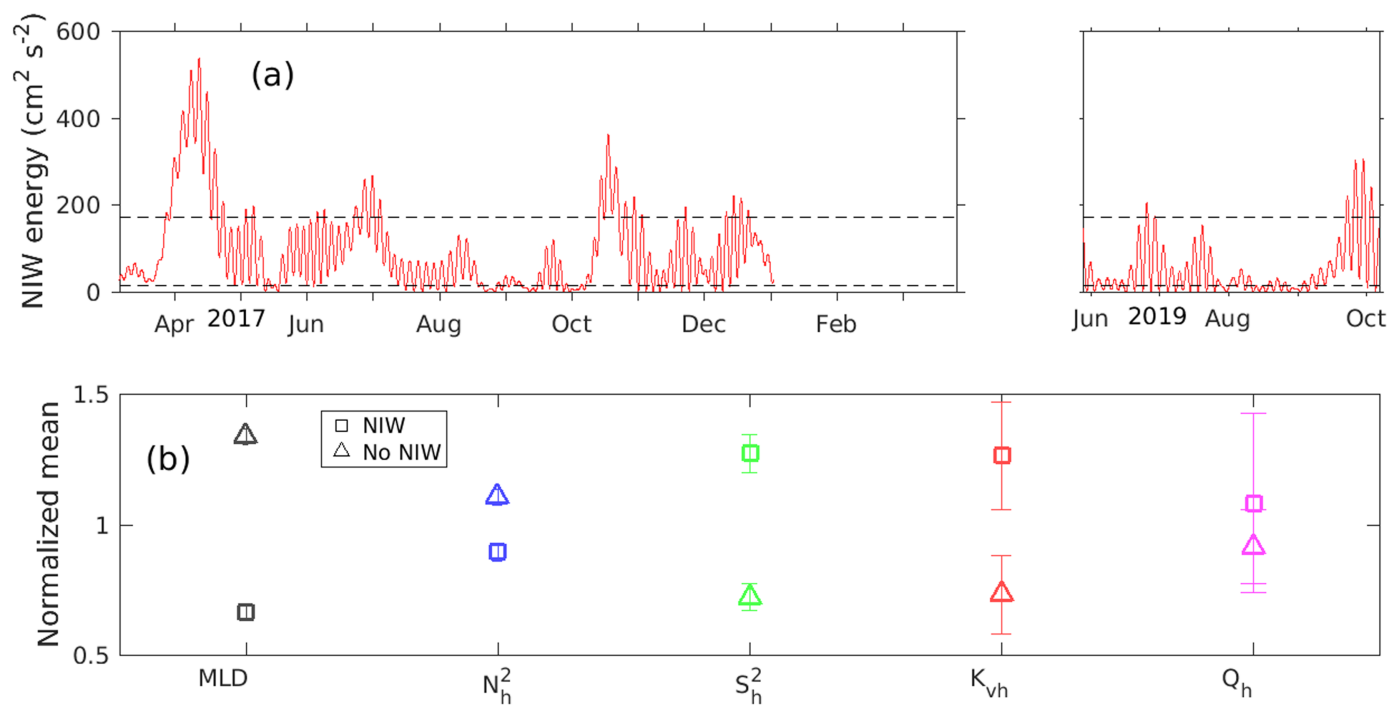

Figure 11. Near-inertial wave (NIW) activity at $4^{\circ} \mathrm{N}$. (a) NIW energy, defined as the square of the hourly NIW current speeds at a depth of $7 \mathrm{~m}$ (red), and thresholds used to define strong and weak NIW activity (dashed black lines). (b) Composites for high- and low-NIW activity, based on values above and below the upper and lower thresholds, respectively, in (a). All values have been divided by their respective means calculated from all high- and low-NIW periods combined. The means are $33 \mathrm{~m}, 2.2 \times 10^{-4} \mathrm{~s}^{-2}, 1.5 \times 10^{-4} \mathrm{~s}^{-2}, 1.8 \times 10^{-4} \mathrm{~m}^{2} \mathrm{~s}^{-1}$, and $-14 \mathrm{~W} \mathrm{~m}^{-2}$ for MLD, $N_{h}^{2}, S_{h}^{2}, K_{v h}$, and $Q_{h}$, respectively. Error bars in panel (b) represent 2 standard errors from the mean.

of seasonality (compare solid and dashed curves in Figure 13a). There are also some similarities between $Q_{h}$ from KPP and KWB and $Q_{h}$ calculated from the mooring heat budget residual (blue curve in Figure 13a). All three estimates show stronger cooling in May-July compared to August-October. The largest discrepancy is in February-April, when KPP and KWB predict very little cooling and the heat budget residual shows cooling of $30-35 \mathrm{~W} \mathrm{~m}^{-2}$.
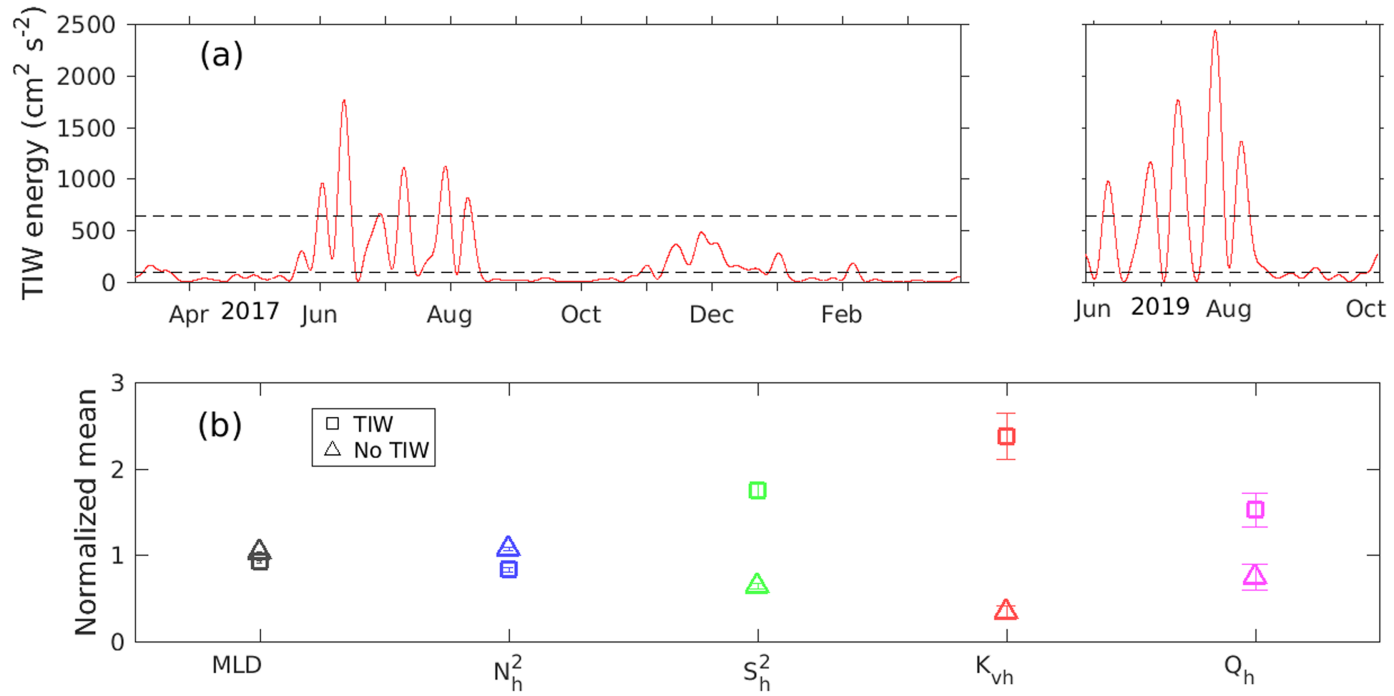

Figure 12. Tropical instability wave (TIW) activity at $4^{\circ} \mathrm{N}$. (a) TIW energy, defined as the square of the hourly TIW current speeds at a depth of $7 \mathrm{~m}$ (red), and thresholds used to define strong and weak TIW activity (dashed black lines). (b) Composites for high- and low-TIW activity, based on values above and below the upper and lower thresholds, respectively, in (a). All values have been divided by their respective means calculated from all high- and low-TIW periods combined. The means are $45 \mathrm{~m}, 2.2 \times 10^{-4} \mathrm{~s}^{-2}, 1.3 \times 10^{-4} \mathrm{~s}^{-2}, 1.7 \times 10^{-4} \mathrm{~m}^{2} \mathrm{~s}^{-1}$, and $-25 \mathrm{~W} \mathrm{~m}^{-2}$ for MLD, $N_{h}^{2}$, $S_{h}^{2}, K_{v h}$, and $Q_{h}$, respectively. Error bars in panel (b) represent 2 standard errors from the mean. 


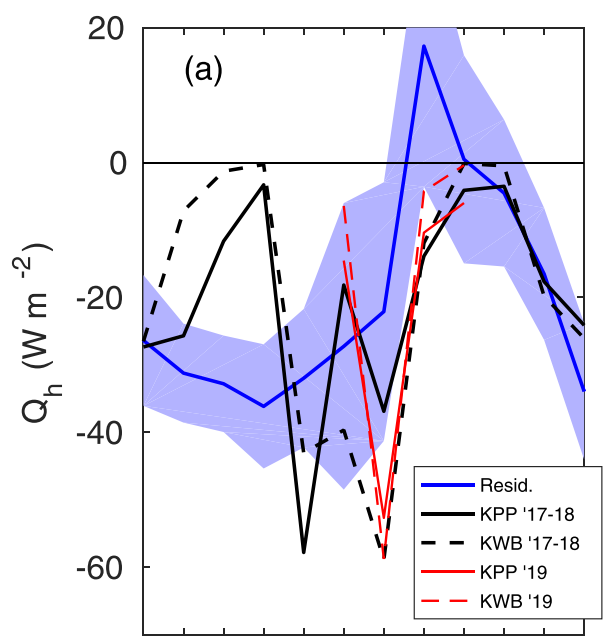

JFMAM J JASOND

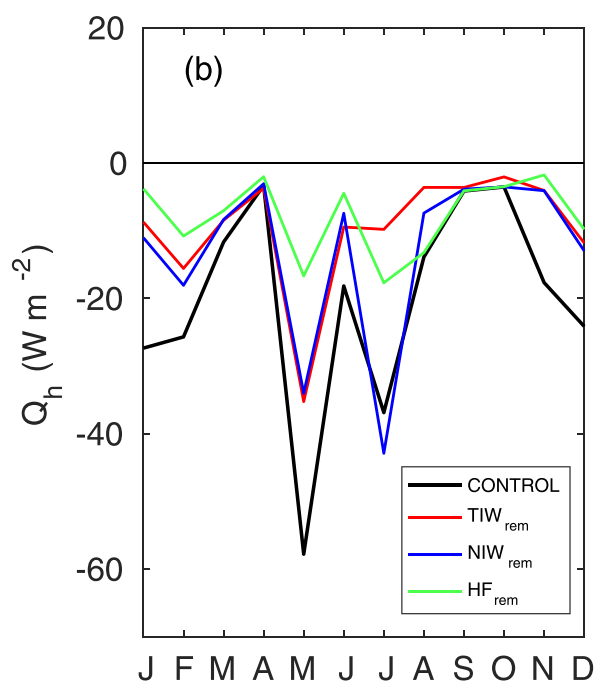

Figure 13. Seasonal cycle of turbulent cooling at $4^{\circ} \mathrm{N}$. (a) Monthly climatology (2006-2017) of the ePIRATA mixed layer heat budget residual (blue) and monthly estimates of the vertical turbulent heat flux across the base of the mixed layer from KPP during March 2017 to March 2018 (solid black) and June-September 2019 (solid red). Dashed black and red lines show estimates from KWB. Blue shading indicates error estimates for the heat budget residual. (b) Vertical turbulent heat flux from KPP during 2017-2018 (black; same as black curve in panel a). Colors indicate results from experiments in which temperature, salinity, and velocity at all depths were averaged to their daily means (green), inertial frequencies were removed (blue), and TIW frequencies were removed (red).

Variability on several different time scales contributes to $Q_{h}$ at $4^{\circ} \mathrm{N}$, based on experiments with KPP during 2017-2018 (Figure 13b). High-frequency variability (periods less than 2 days, excluding the diurnal cycle) appears to generate the most cooling over the course of the year (compare black curve (CONTROL) in Figure $13 \mathrm{~b}$ to green curve $\left(\mathrm{HFV}_{\text {rem }}\right)$ ). Consistent with the composite results presented earlier, the diurnal cycle does not contribute strongly, explaining only about $25 \%$ of $Q_{h}$ in May and close to zero during other months. Most of the reduction in $Q_{h}$ in $\mathrm{HFV}_{\text {rem }}$ compared to CONTROL is due to variability with periods less than $20 \mathrm{hr}$. NIWs are less important than high-frequency variability but are responsible for $\sim 10 \mathrm{~W} \mathrm{~m}^{-2}$ of cooling on average during November-February and about $20 \mathrm{~W} \mathrm{~m}^{-2}$ in May (difference between blue and black curves in Figure 13b). The impact of TIWs on $Q_{h}$ is similar to that of NIWs with the exception of July, when TIWs are responsible for more than $30 \mathrm{~W} \mathrm{~m}^{-2}$ of cooling compared to slight warming for NIWs (compare red and blue curves in Figure 13b). During most months, the sum of $Q_{h}$ from TIWs, NIWs, and high-frequency variability exceeds the cooling from the model's control run, indicating that there are nonlinear effects operating across time scales. This is not surprising, given the nonlinear nature of mixing, and it makes the total contribution from any one process difficult to quantify exactly. 

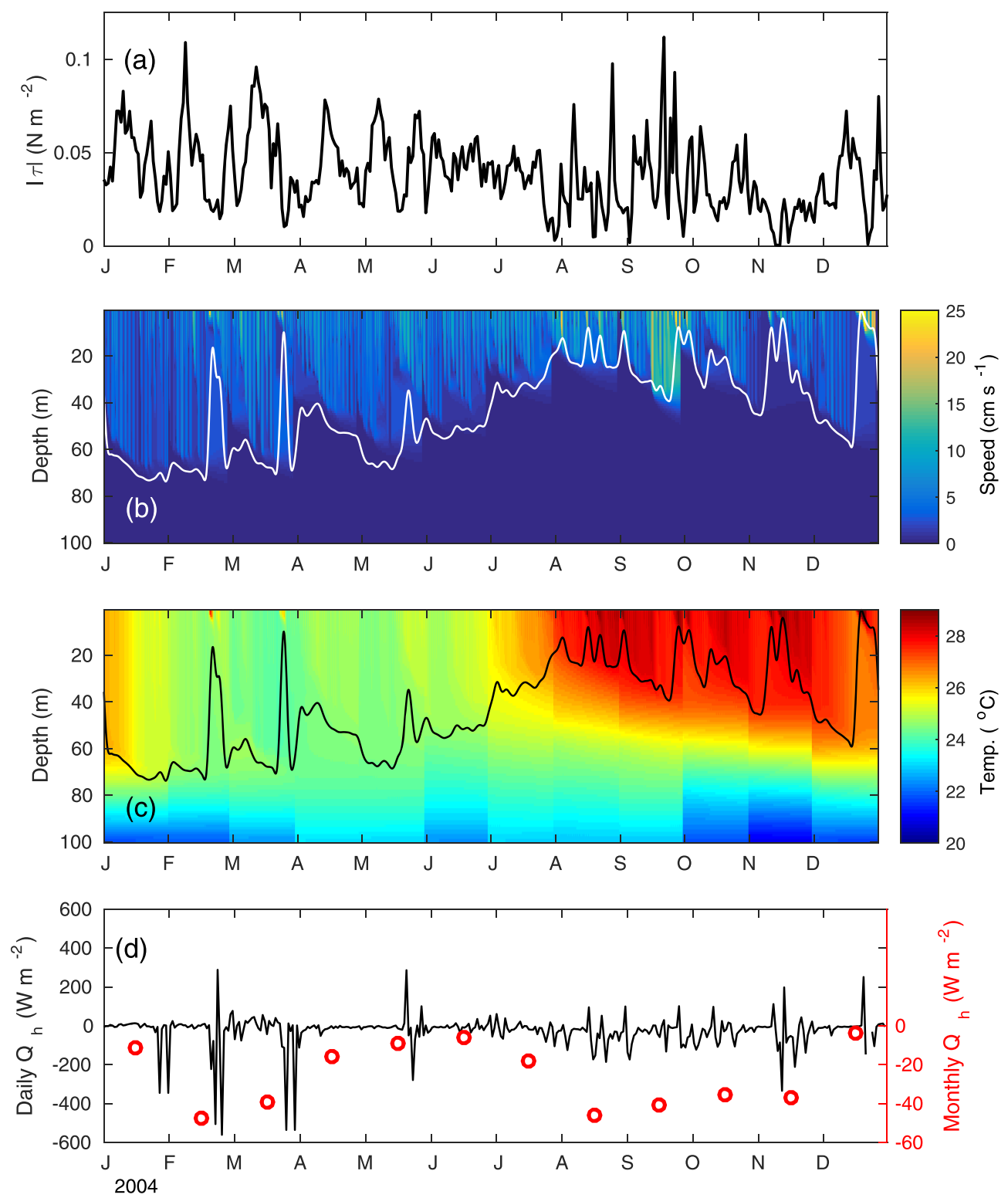

Figure 14. Wind forcing and output from the PWP model at $15^{\circ} \mathrm{N}, 38^{\circ} \mathrm{W}$ during 2004. (a) Wind stress magnitude. (b) Current speed (shaded) and mixed layer depth smoothed with a 5-day low-pass filter (white line). (c) Temperature (shaded) and smoothed mixed layer depth (black line). Discontinuous jumps at the beginning of each month are due to reinitialization of the PWP model. (d) Daily (black) and monthly mean (red circles) vertical turbulent heat flux, calculated as the heat budget residual from the PWP model.

\subsection{Trade Wind Region: $15^{\circ} \mathrm{N}, 38^{\circ} \mathrm{W}$}

The PIRATA mooring at $15^{\circ} \mathrm{N}$ is located to the north of the ITCZ throughout most of the year, in contrast to $4^{\circ} \mathrm{N}$. Mean wind stress is higher at $15^{\circ} \mathrm{N}$, with a record length mean of $0.052 \mathrm{~N} \mathrm{~m}^{-2}$, more than double that at $4^{\circ} \mathrm{N}, 23^{\circ} \mathrm{W}\left(0.025 \mathrm{~N} \mathrm{~m}^{-2}\right)$. At $15^{\circ} \mathrm{N}$, the weakest winds occur during August-November (shown for 2004 in Figure 14a), compared to December-June at $4^{\circ} \mathrm{N}$. At $15^{\circ} \mathrm{N}$ the SD of daily wind stress magnitude during August-November is almost twice as large as that during the December-June low-wind period at $4^{\circ} \mathrm{N}\left(0.021 \mathrm{~N} \mathrm{~m}^{-2}\right.$ compared to $\left.0.012 \mathrm{~N} \mathrm{~m}^{-2}\right)$. Despite differences in winds, the seasonal amplitudes of MLD are similar between the locations, ranging from $\sim 20 \mathrm{~m}$ to $60-80 \mathrm{~m}$, with smallest values when winds are weakest (Figure 14b). We show only the results from 2004 in Figure 14 in order to emphasize submonthly time scales, but results are similar for the other years considered (2001-2003, 2006, 2007, and 2012). 


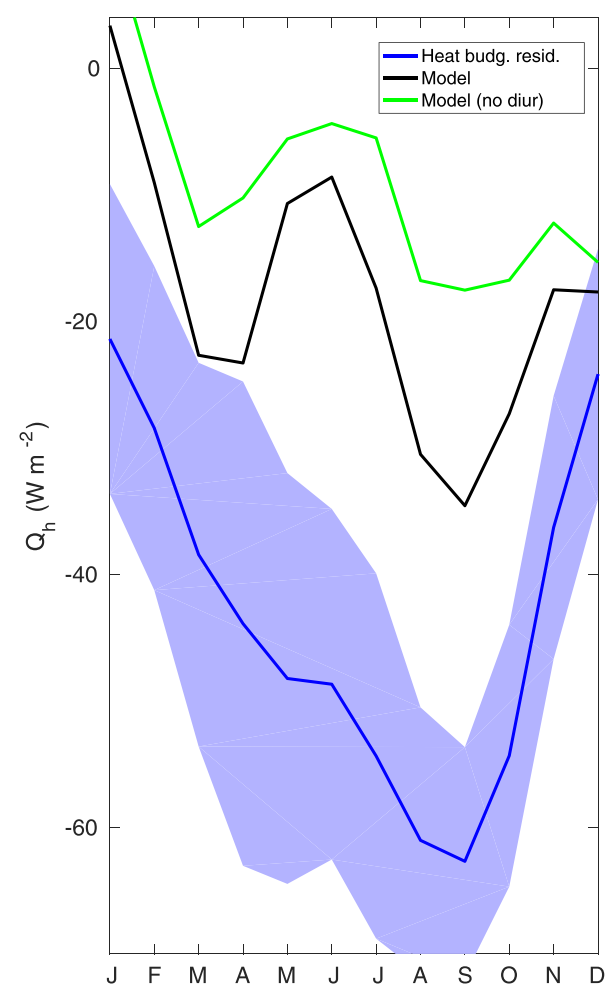

Figure 15. Seasonal cycle of the vertical turbulent heat flux across the base of the mixed layer $\left(Q_{h}\right)$ at $15^{\circ} \mathrm{N}$. Monthly climatology (1998-2017) of $Q_{h}$ estimated from the ePIRATA mixed layer heat budget residual (blue) and monthly climatology (2001-2004, 2006, 2007, and 2012) of $Q_{h}$ calculated from the PWP model's heat budget residual (black). Green curve is $Q_{h}$ from PWP forced with daily mean solar radiation instead of hourly. Blue shading indicates error estimates for the ePIRATA heat budget residual.
Variability of near-surface currents at $15^{\circ} \mathrm{N}$ is strongest during August-September, when the mixed layer is thinnest. Note that the velocity field at this location is obtained from the PWP model, which is forced only with local winds and surface fluxes and does not include any remote influences. Large increases in current speed occur during sharp increases in wind stress that follow calmer conditions (Figure 14b). During these events, NIWs are excited in the mixed layer (upper 30-40 m). The calm conditions preceding the wind events allow SST to increase by as much as $2{ }^{\circ} \mathrm{C}$ (Figure 14c). Strong mixing and turbulent cooling then occur with the increasing wind, thickening the mixed layer by $10-20 \mathrm{~m}$ over several days and entraining colder water from below (Figures 14c and 14d). Here turbulent cooling has been estimated as the residual in the heat budget from PWP (equation (3)). Periods of positive turbulent heat flux in the model (i.e., tending to warm the mixed layer) tend to occur near the peak of the diurnal cycle, when SST is highest and the mixed layer is thinnest. When the net surface heat flux briefly becomes negative due to cloudiness, the model's ocean surface cools and entrains warmer water from below. In contrast, stronger cooling generally follows later in the day as the net surface heat flux becomes negative for a more extended period of time and the mixed layer thickens and entrains colder water from greater depths. The monthly mean vertical turbulent heat flux shows two peaks of cooling with similar magnitudes ( $\sim 40-50$ $\mathrm{W} \mathrm{m}^{-2}$; red circles in Figure 14d): one in February-March and another during August-November. Both correspond to periods with strong variability of wind stress and MLD (Figures 14a and 14b).

The seasonal cycle of the PWP heat budget residual (an estimate of turbulent cooling) at $15^{\circ} \mathrm{N}$, averaged over all years (2001-2004, 2006, 2007, and 2012), is generally consistent with the results from 2004 (compare red circles in Figure 14d to black curve in Figure 15). Cooling peaks in September at about $30 \mathrm{~W} \mathrm{~m}^{-2}$, when winds are weakest on average and the mixed layer is thin, and there is a secondary peak in March-April. When the model is forced with daily solar radiation instead of hourly, the annual mean vertical turbulent cooling decreases from 18 to $9 \mathrm{~W} \mathrm{~m}^{-2}$ and the seasonal amplitude, defined as the maximum climatological monthly cooling minus the minimum, decreases from 31 to $28 \mathrm{~W} \mathrm{~m}^{-2}$ (compare black and green curves in Figure 15). This suggests that the net cooling from the diurnal cycle (due to nighttime surface cooling and thickening of the mixed layer) is more important in the annual mean than for the seasonal cycle. This is different than the results at $4^{\circ} \mathrm{N}$, where the diurnal cycle was found not to have an impact on the mean turbulent cooling.

The magnitude of the modeled cooling at $15^{\circ} \mathrm{N}$ is smaller than that inferred from the ePIRATA heat budget residual, which reaches $60 \mathrm{~W} \mathrm{~m}^{-2}$ in September, but the phases are similar (black and blue curves in Figure 15). The model's smaller amplitude is likely due in part to its underestimation of near-inertial currents and lack of any remote forcing (Figures $5 \mathrm{c}$ and $5 \mathrm{~d}$ ). It is also possible that there are important mixing processes in addition to those caused directly by the local wind and surface buoyancy flux, the only processes included in the PWP model. Based on the results at $4^{\circ} \mathrm{N}$, we expect that high-frequency variations in shear are also important at $15^{\circ} \mathrm{N}$. This variability is missing in the PWP model because it does not account for nonlocal forcing such as internal waves. To test this, we ran the PWP model at $4^{\circ} \mathrm{N}$ following the methods used at $15^{\circ} \mathrm{N}$ and found that the SDs of zonal and meridional velocities with periods less than 2 days are underestimated by about a factor of 40-50 in the upper $20 \mathrm{~m}$ compared to direct measurements from the $4^{\circ} \mathrm{N}$ mooring: PWP SDs range from $0.1-0.25 \mathrm{~cm} \mathrm{~s}^{-1}$ compared to $6-9 \mathrm{~cm} \mathrm{~s}^{-1}$ from the mooring. The underestimation is even greater at deeper levels $(47-87 \mathrm{~m})$, where the SDs of the observed velocities remain at 6-9 $\mathrm{cm} \mathrm{s}^{-1}$ and the PWP SDs drop to less than $0.05 \mathrm{~cm} \mathrm{~s}^{-1}$. Consistent with what was found at $15^{\circ} \mathrm{N}$ (Figures $5 \mathrm{c}$ and 5d), the PWP model also underestimates near-inertial velocity variability in the upper $40 \mathrm{~m}$ at $4^{\circ} \mathrm{N}$ by a factor of about 6-8 compared to direct measurements from the mooring. 
Despite these limitations of the model, the results at $15^{\circ} \mathrm{N}$ are generally consistent with those at $4^{\circ} \mathrm{N}$. At both locations the maximum cooling occurs at the time of year when winds are weakest on average and the mixed layer is thinnest. During the seasons with strongest turbulent cooling (boreal winter-spring at $4^{\circ} \mathrm{N}$ and boreal summer-fall at $15^{\circ} \mathrm{N}$ ), it appears that multiple processes on different time scales may be needed to generate the mixing. When variability on one time scale is removed (TIWs, NIWs, or periods less than 2 days at $4^{\circ} \mathrm{N}$ ) or significantly reduced (NIWs and subinertial periods at $15^{\circ} \mathrm{N}$ in PWP), the cooling is much weaker compared to that of the control run at $4^{\circ} \mathrm{N}$ and that inferred from the ePIRATA heat budget residual at $15^{\circ} \mathrm{N}$.

\section{Summary and Discussion}

The seasonal cycles of vertical turbulent cooling were investigated at two PIRATA mooring locations: one in the eastern ITCZ region $\left(4^{\circ} \mathrm{N}, 23^{\circ} \mathrm{W}\right)$ and one in the trade wind region $\left(15^{\circ} \mathrm{N}, 38^{\circ} \mathrm{W}\right)$. At $4^{\circ} \mathrm{N}$ turbulent cooling was found to be strongest on average in boreal winter and spring, when winds are weakest and the mixed layer is thinnest. During summer, winds increase, the mixed layer thickens, and turbulent cooling across the base of the mixed layer decreases. The amplitude of the seasonal cycle of turbulent cooling is modest, with a peak to peak monthly difference of about $50 \mathrm{~W} \mathrm{~m}^{-2}$.

Composite analysis of strong diurnal warming events showed that the largest shear variance, diffusivity, and turbulent cooling at the base of the mixed layer occur at night and in the early morning, when the mixed layer is thickest. However, no rectification onto the mean turbulent cooling was found. Strong NIWs were found to be associated with a thinner mixed layer, stronger shear, and stronger mixing, on average, compared to periods without NIW activity, but there was not a significant difference in turbulent cooling between high- and low-NIW energy periods. Sensitivity tests with the KPP mixing parameterization confirm the importance of variability on multiple time scales, from subdiurnal to inertial and intraseasonal. Enhanced shear from TIWs was found to drive monthly turbulent cooling of 10-30 W m ${ }^{-2}$ during May-July in 2017 and 2019.

At $15^{\circ} \mathrm{N}$, turbulent cooling was also found to be strongest during the time of year when the mixed layer is thinnest and winds are weakest (boreal summer and fall). The pronounced seasonality was found in a one-dimensional model and the observed heat budget residual. However, there is more uncertainty in the causes of the seasonality at this location because direct measurements of current shear are not available from the PIRATA mooring. The model used to estimate velocity at this location (PWP) was not capable of generating geostrophic shear or remotely generated signals such as internal waves, as only locally forced phenomena are present. As a result, the seasonal amplitude of turbulent cooling estimated by the model was about 50\% weaker than that inferred from the observed heat budget residual. It is likely that the absence of superinertial velocity shear and the weaker than observed near-inertial currents in the model were major factors that caused its underestimation of turbulent cooling, though this needs further investigation.

Our results in the ITCZ and trade wind regions contrast with those in the equatorial Atlantic, where the seasonal intensification of the trade winds strengthens surface and subsurface currents and shear-induced mixing (Hummels et al., 2013; Jouanno et al., 2011). Off the equator, we found the opposite: strengthening winds act to deepen the mixed layer and this period of stronger winds and thicker mixed layer is associated with reduced shear-induced mixing. The strong seasonal cycles of turbulent cooling at many off-equatorial locations, and the complex interplay of shear and stratification across a range of time scales, emphasize the need for multiyear measurements of velocity shear and stratification, and ideally microstructure, at one or more PIRATA moorings. The velocity and temperature measurements should be at least hourly and have a vertical resolution of $5 \mathrm{~m}$ or better in order to resolve small-scale velocity shear (Perez et al., 2019). In our study we could not diagnose the importance of salinity for mixing because of the coarse vertical spacing of salinity sensors on the moorings. Additional conductivity sensors in the upper $100 \mathrm{~m}$ (ideally positioned every 5-10 m) would be very helpful for this purpose.

\section{References}

Alford, M. H., MacKinnon, J. A., Simmons, H. L., \& Nash, J. D. (2016). Near-inertial internal gravity waves in the ocean. Annual Review of Marine Science, 8, 95-123.

Athie, G., \& Marin, F. (2008). Cross-equatorial structure and temporal modulation of intraseasonal variability at the surface of the tropical Atlantic Ocean. Journal of Geophysical Research, 113, C08020. https://doi.org/10.1029/2007JC004332 
Bourlès, B., Araujo, M., McPhaden, M., Brandt, P., Foltz, G. R., Lumpkin, R., et al. (2019). PIRATA: A sustained observing system for tropical Atlantic climate research and forecasting. Earth and Space Science, 6, 577-616. https://doi.org/10.1029/2018EA000428

Caltabiano, A. C. V., Robinson, I. S., \& Pezzi, L. P. (2005). Multi-year satellite observations of instability waves in the tropical Atlantic Ocean. Ocean Science, 1, 97-112. https://doi.org/10.5194/os-1-97-2005

Carton, J. A., \& Huang, B. H. (1994). Warm events in the tropical Atlantic. Journal of Physical Oceanography, $24,888-903$.

Carton, J. A., \& Zhou, Z. X. (1997). Annual cycle of sea surface temperature in the tropical Atlantic Ocean. Journal of Geophysical Research, $102,27,813-27,824$.

Chiang, J. C. H., Kushnir, Y., \& Giannini, A. (2002). Deconstructing Atlantic Intertropical Convergence Zone variability: Influence of the local cross-equatorial sea surface temperature gradient and remote forcing from the eastern equatorial Pacific. Journal of Geophysical Research, 107, 4004. https://doi.org/10.1029/2000JD000307

Cintra, M. M., Lentini, C. A. D., Servain, J., Araujo, M., \& Marone, E. (2015). Physical processes that drive the seasonal evolution of the southwestern tropical Atlantic warm pool. Dynamics of Atmospheres and Oceans, 72, 1-11.

D'Asaro, E. A. (1985). The energy flux from the wind to near-inertial motions in the surface mixed layer. Journal of Physical Oceanography, $15,1043-1059$.

Fer, I., Peterson, A. K., \& Ullgren, J. E. (2014). Microstructure measurements from an underwater glider in the turbulent Faroe bank channel overflow. Journal of Atmospheric and Oceanic Technology, 31, 1128-1150. https://doi.org/10.1175/JTECH-D-13-00221.1

Foltz, G. R., Brandt, P., Richter, I., Rodrúguez-Fonseca, B., Hernandez, F., Dengler, M., et al. (2019). The tropical Atlantic observing system. Frontiers in Marine Science, 6, 206. https://doi.org/10.3389/fmars.2019.00206

Foltz, G. R., Grodsky, S. A., Carton, J. A., \& McPhaden, M. J. (2003). Seasonal mixed layer heat budget of the tropical Atlantic Ocean. Journal of Geophysical Research, 108(C5), 3146. https://doi.org/10.1029/2002JC001584

Foltz, G. R., \& McPhaden, M. J. (2009). Impact of barrier layer thickness on SST in the central tropical North Atlantic. Journal of Climate, $22,285-299$.

Foltz, G. R., Schmid, C., \& Lumpkin, R. (2013). Seasonal cycle of the mixed layer heat budget in the northeastern tropical Atlantic Ocean. Journal of Climate, 26, 8169-8188. https://doi.org/10.1175/JCLI-D-13-00037.1

Foltz, G. R., Schmid, C., \& Lumpkin, R. (2018). An enhanced PIRATA data set for tropical Atlantic Ocean-atmosphere research. Journal of Climate, 31, 1499-1524. https://doi.org/10.1175/JCLI-D-16-0816.1

Gentemann, C. L., Donlon, C. J., Stuart-Menteth, A., \& Wentz, F. J. (2003). Diurnal signals in satellite sea surface temperature measurements. Geophysical Research Letters, 30(3), 1140. https://doi.org/10.1029/2002GL016291

Giordani, H., Caniaux, G., \& Voldoire, A. (2013). Intraseasonal mixed-layer heat budget in the equatorial Atlantic during the cold tongue development in 2006. Journal of Geophysical Research: Oceans, 118, 650-671. https://doi.org/10.1029/2012JC008280

Good, S. A., Martin, M. J., \& Rayner, N. A. (2013). EN4: Quality controlled ocean temperature and salinity profiles and monthly objective analyses with uncertainty estimates. Journal of Geophysical Research: Oceans, 118, 6704-6716. https://doi.org/10.1002/2013JC009067

Goodman, L., Levine, E. R., \& Lueck, R. G. (2006). On measuring the terms of the turbulent kinetic energy budget from an AUV. Journal of Atmospheric and Oceanic Technology, 23, 977-990. https://doi.org/10.1175/JTECH1889.1

Grodsky, S. A., Carton, J. A., Provost, C., Servain, J., Lorenzzetti, J. A., \& McPhaden, M. J. (2005). Tropical instability waves at $0^{\circ} \mathrm{N}, 23^{\circ} \mathrm{W}$ in the Atlantic: A case study using Pilot Research Moored Array in the Tropical Atlantic (PIRATA) mooring data. Journal of Geophysical Research, 110, C08010. https://doi.org/10.1029/2005JC002941

Hummels, R., Dengler, M., \& Bourlès, B. (2013). Seasonal and regional variability of upper ocean diapycnal heat flux in the Atlantic cold tongue. Progress in Oceanography, 111, 52-74. https://doi.org/10.1016/j.pocean.2012.11.001

Hummels, R., Dengler, M., Brandt, P., \& Schlundt, M. (2014). Diapycnal heat flux and mixed layer heat budget within the Atlantic cold tongue. Climate Dynamics, 43, 3179-3199. https://doi.org/10.1007/s00382-014-2339-6

Inoue, R., Lien, R. C., \& Moum, J. N. (2012). Modulation of equatorial turbulence by a tropical instability wave. Geophysical Research Letters, 117, C10009. https://doi.org/10.1029/2011JC007767

Inoue, R., Lien, R. C., Moum, J. N., Perez, R. C., \& Gregg, M. C. (2019). Variations of equatorial shear, stratification, and turbulence within a tropical instability wave cycle. Journal of Geophysical Research: Oceans, 124, 1858-1875. https://doi.org/10.1029/2018JC014480

Jochum, M., Briegleb, B. P., Danabasoglu, G., Large, W. G., Norton, N. J., Jayne, S. R., et al. (2013). The impact of oceanic near-inertial waves on climate. Journal of Climate, 26, 2833-2844.

Jochum, M., Malanotte, Rizzoli, \& Busalacchi, A. J. (2004). Tropical instability waves in the Atlantic Ocean. Ocean Modelling, 7, 145-163.

Jouanno, J., Marin, F., duPenhoat, Y., Sheinbaum, J., \& Molines, J. (2011). Seasonal heat balance in the upper $100 \mathrm{~m}$ of the equatorial Atlantic Ocean. Journal of Geophysical Research, 116, C09003. https://doi.org/10.1029/2010JC006912

Keenlyside, N. S., \& Latif, M. (2007). Understanding equatorial Atlantic interannual variability. Journal of Climate, $20,131-142$.

Kraus, E. B. (1972). Atmosphere-ocean interaction, vol. 275, pp. 1972: Oxford, England.

Kumar, B. P., Vialard, J., Lengaigne, M., Murty, V. S. N., \& McPhaden, M. J. (2012). Tropflux: Air-sea fluxes for the global tropical oceans-Description and evaluation. Climate Dynamics, 38, 1521-1543. https://doi.org/10.1007/s00382-011-1115-0

Kunze, E., Williams, A. J., \& Briscoe, M. G. (1990). Observations of shear and vertical stability from a neutrally buoyant float. Journal of Geophysical Research, 95, 18,127-18,142. https://doi.org/10.1029/JC095iC10p18127

Large, W. G., McWilliams, J. C., \& Doney, S. C. (1994). Oceanic vertical mixing-A review and a model with a nonlocal boundary-layer parameterization. Reviews of Geophysics, 32, 363-403. https://doi.org/10.1029/94RG01872

MacKinnon, J. A., Zhao, Z. X., Whalen, C. B., Waterhouse, A. F., Trossman, D. S., Sun, O. M., et al. (2017). Climate process team on internal wave-driven ocean mixing. Bulletin of the American Meteorological Society, 98, 2429-2454.

Martín-Rey, M., Polo, I., Rodrguez-fonseca, B., Losada, T., \& Lazar, A. (2018). Is there evidence of changes in tropical Atlantic variability modes under AMO phases in the observational record? Journal of Climate, 31, 515-536.

McPhaden, M. J., Cronin, M. F., \& McClurg, D. C. (2008). Meridional structure of the seasonally varying mixed layer temperature balance in the eastern tropical Pacific. Journal of Climate, 21, 3240-3260. https://doi.org/10.1175/2007JCLI2115.1

Merckelbach, L., Berger, A., Krahmann, G., Dengler, M., \& Carpenter, J. R. (2019). A dynamic flight model for Slocum gliders and implications for turbulence microstructure measurements. Journal of Atmospheric and Oceanic Technology, 36, 281-296. https://doi.org/ 10.1175/JTECH-D-18-0168

Mitchell, T. P., \& Wallace, J. M. (1992). The annual cycle in equatorial convection and sea surface temperature. Journal of Climate, 5 , 1140-1156.

Moum, J. N., Lien, R. C., Perlin, A., Nash, J. D., Gregg, M. C., \& Wiles, P. J. (2009). Sea surface cooling at the equator by subsurface mixing in tropical instability waves. Nature Geoscience, 2, 761-765. https://doi.org/10.1038/NGEO657

Moum, J. N., Perlin, A., Nash, J. D., \& McPhaden, M. J. (2013). Seasonal sea surface cooling in the equatorial Pacific cold tongue controlled by ocean mixing. Nature, 500, 64-67. https://doi.org/10.1038/nature12363 
Nobre, C., \& Shukla, J. (1996). Variation of sea surface temperature, wind stress, and rainfall over the tropical Atlantic and South America. Journal of Climate, 9, 2464-2479.

Nogueira Neto, A. V., Giordani, H., Caniaux, G., \& Araujo, M. (2018). Seasonal and interannual mixed-layer heat budget variability in the western tropical Atlantic from argo floats (2007-2012). Journal of Geophysical Research: Oceans, 123, 5298-5322. https://doi.org/10. 1029/2017JC013436

Osborn, T. R. (1980). Estimates of the local rate of vertical diffusion from dissipation measurements. Journal of Physical Oceanography, 10, 83-89.

Paulson, C. A., \& Simpson, J. J. (1977). Irradiance measurements in the upper ocean. Journal of Physical Oceanography, 7, 952-956.

Perez, R. C., Foltz, G. R., Lumpkin, R., \& Schmid, C. (2019). Direct measurements of upper ocean horizontal velocity and vertical shear in the tropical North Atlantic Ocean at $4^{\circ} \mathrm{N}, 23^{\circ} \mathrm{W}$. Journal of Geophysical Research: Oceans, 124, 4133-4151. https://doi.org/10.1029/ 2019JC015064

Perez, R. C., Lumpkin, R., Johns, W. E., Foltz, G. R., \& Hormann, V. (2012). Interannual variations of Atlantic tropical instability waves. Journal of Geophysical Research, 117, C03011. https://doi.org/10.1029/2011JC007584

Peter, A. C., Le Henaff, M., Penhoat, Y., Menkes, C. E., Marin, F., Vialard, J., et al. (2006). A model study of the seasonal mixed layer heat budget in the equatorial Atlantic. Journal of Geophysical Research, 111, C06014. https://doi.org/10.1029/2005JC003157

Peters, H., Gregg, M. C., \& Sanford, T. B. (1995). On the parameterization of equatorial turbulence: Effect of fine-scale variations below the range of the diurnal cycle. Journal of Geophysical Research, 100, 18,333,-18,348. https://doi.org/10.1029/95JC01513

Pollard, R. T., \& Millard, R. C. (1970). Comparison between observed and simulated wind-generated inertial oscillations. Deep Sea Research and Oceanographic Abstracts, 17, 813-821. https://doi.org/10.1016/0011-7471(70)90043-4

Polzin, K. (1996). Statistics of the Richardson number: Mixing models and fine structure. Journal of Physical Oceanography, 26, 1409-1425. https://doi.org/10.1175/1520-0485(1996)026<1409:SOTRNM>2.0.CO;2.

Price, J., Weller, R., \& Pinkel, R. (1986). Diurnal cycling: Observations and models of the upper ocean response to diurnal heating, cooling and wind mixing. Journal of Geophysical Research, 91, 8411-8427.

Rhein, M., \& Dengler, M. (2010). Upwelling and associated heat flux in the equatorial Atlantic inferred from helium isotope disequilibrium. Journal of Geophysical Research, 115, C08021. https://doi.org/10.1029/2009JC005772

Rugg, A., Foltz, G. R., \& Perez, R. C. (2016). Role of mixed layer dynamics in tropical North Atlantic interannual sea surface temperature variability. Journal of Climate, 29, 8083-8101. https://doi.org/10.1175/JCLI-D-1500867.1

Schafstall, J., Dengler, M., Brandt, P., \& Bange, H. (2010). Tidal induced mixing and diapycnal nutrient fluxes in the Mauritanian upwelling region. Journal of Geophysical Research, 115, C10014. https://doi.org/10.1029/2009JC005940

Smyth, W. D., Skyllingstad, E. D., Crawford, G. B., \& Wijesekera, H. (2002). Nonlocal fluxes and stokes drift effects in the $k$-profile parameterization. Ocean Dynamics, 52, 104-115.

Stevenson, J. W., \& Niiler, P. P. (1983). Upper ocean heat budget during the Hawaii-to-Tahiti shuttle experiment. Journal of Physical Oceanography, 13, 1894-1907.

Swenson, M. S., \& Hansen, D. V. (1999). Tropical Pacific Ocean mixed layer heat budget: The Pacific cold tongue. Journal of Physical Oceanography, 29, 69-81.

von Schuckmann, K., Brandt, P., \& Eden, C. (2008). Generation of tropical instability waves in the Atlantic Ocean. Journal of Geophysical Research, 113, C08034. https://doi.org/10.1029/2007JC004712

Wade, M., Caniaux, G., DuPenhoat, Y., Dengler, M., Giordani, H., \& Hummels, R. (2011). A one-dimensional modeling study of the diurnal cycle in the equatorial Atlantic at the PIRATA buoys during the EGEE-3 campaign. Ocean Dynamics, 61, 1-20.

Wang, W. M., \& McPhaden, M. J. (1999). The surface-layer heat balance in the equatorial Pacific Ocean. Part I: Mean seasonal cycle. Journal of Physical Oceanography, 29, 1812-1831.

Wenegrat, J. O., \& McPhaden, M. J. (2015). Dynamics of the surface layer diurnal cycle in the equatorial Atlantic Ocean $\left(0^{\circ}, 23^{\circ} \mathrm{W}\right) . \mathrm{Journal}$ of Geophysical Research: Oceans, 120, 563-581. https://doi.org/10.1002/2014JC010504

Yu, L. S., Jin, X. Z., \& Weller, R. A. (2006). Role of net surface heat flux in seasonal variations of sea surface temperature in the tropical Atlantic Ocean. Journal of Climate, 19, 6153-6169. 